\title{
Microbial Arsenal of Antiviral Defenses - Part I
}

\author{
Artem B. Isaev ${ }^{1, a *}$, Olga S. Musharova ${ }^{1,2, b}$, and Konstantin V. Severinov ${ }^{1,3, c *}$ \\ ${ }^{1}$ Skolkovo Institute of Science and Technology, 143028 Moscow, Russia \\ ${ }^{2}$ Institute of Molecular Genetics, 119334 Moscow, Russia \\ ${ }^{3}$ Waksman Institute of Microbiology, Piscataway, NJ 08854, USA \\ ae-mail:tcft18@gmail.com \\ ${ }^{b}$ e-mail:olga.musharova@skolkovotech.ru \\ ${ }^{c} e$-mail:severik@waksman.rutgers.edu
}

Received August 10, 2020

Revised August 18, 2020

Accepted September 12, 2020

\begin{abstract}
Bacteriophages or phages are viruses that infect bacterial cells (for the scope of this review we will also consider viruses that infect Archaea). Constant threat of phage infection is a major force that shapes evolution of the microbial genomes. To withstand infection, bacteria had evolved numerous strategies to avoid recognition by phages or to directly interfere with phage propagation inside the cell. Classical molecular biology and genetic engineering have been deeply intertwined with the study of phages and host defenses. Nowadays, owing to the rise of phage therapy, broad application of CRISPR-Cas technologies, and development of bioinformatics approaches that facilitate discovery of new systems, phage biology experiences a revival. This review describes variety of strategies employed by microbes to counter phage infection, with a focus on novel systems discovered in recent years. First chapter covers defense associated with cell surface, role of small molecules, and innate immunity systems relying on DNA modification.
\end{abstract}

DOI: $10.1134 / \mathrm{S} 0006297921030081$

Keywords: bacteriophages, phage-host interactions, antiviral defense, immunity systems, CRISPR-Cas, restriction-modification, BREX, DISARM, phosphorothioate, Dnd systems

\section{INTRODUCTION}

Phages are found in any natural environment and are considered to be the most abundant biological entities on Earth [1-3]. The estimated numbers of phage particles can be as high as $\sim 10^{10} /$ liter in sea or freshwater and $\sim 10^{9} / \mathrm{g}$ in soil. Overall, phages are thought to outnumber microbial hosts by 10 to 1 or more $[4,5]$. Phages play an important ecological role by controlling the size and diversity of microbial populations [6], while phage-

Abbreviations: BREX, bacteriophage exclusion; CRISPRCas, clustered regularly interspaced repeats and CRISPR-associated proteins; DISARM, defense island system associated with restriction-modification; Dnd, DNA degradation phenotype; PLD, phospholipase D; DPD, 7-deazapurine in DNA; ECM, extracellular matrix; LPS, lipopolysaccharide; MTase, methyltransferase; Pgl, phage growth limitation; PT, phosphorothioate; pVip, prokaryotic viperin; QS, quorum sensing; $\mathrm{RBP}$, receptor binding protein; REase, restriction endonuclease; R-M, restriction-modification; Sie, superinfection exclusion; TA, toxin-antitoxin.

* To whom correspondence should be addressed. induced lysis of cells ensures flow of nutrients through the food networks [7]. Phages greatly enhance lateral gene transfer, and medically relevant bacterial traits are often associated with prophages [8]. Host genes can be incorporated in a viral genome or can be packaged into capsids to generate transducing particles [9]. Besides, bacteria can produce phage-like gene transferring agents carrying host DNA [10]. The spread of plasmids is also facilitated by phage-induced cell lysis [11].

Theoretical works and mathematical models assume that parasitic or selfish genetic elements inevitably emerge in any replicator system and counteracting strategies are required to achieve stable co-existence [1214]. Thus, the presence of phages and host defense systems might be considered as a fundamental property of prokaryotic life. Billions of years of co-evolution resulted in the development of a broad range of offense and defense strategies employed by viruses and their hosts. Genes associated with phage defense can constitute up to $10 \%$ of a microbial genome [15]. Traditionally, discovery of the phage defense systems was associated with selection of phage-resistant strains and characterization of 
their specific traits. Recent increase in the availability of genomic data and application of bioinformatics approaches significantly expanded the field, allowing systematic prediction of novel phage defense gene clusters. A popular "guilt-by-association" approach is based on the fact that functionally linked genes are often colocalized [16]. Using a gene with known function as a "bait", neighboring genes in multiple genomes are assessed for probability to be found in the vicinity of the "bait" to predict possible functional linkage [17]. Applied to the known phage resistance systems this approach allowed to introduce an important concept of defense islands - genomic loci with clusters of antiviral defense genes [18]. An individual genome can contain multiple defense islands. Often, they include mobile genetic elements, which contribute to extensive horizontal gene transfer of defense systems $[19,20]$. Since $\sim 2 / 3$ of the genes in defense islands were not known to be associated with phage resistance, novel types of antiviral systems were predicted [18]. Recently, systematic analysis of all pfam database protein domains encountered in the defense islands within the microbial pan-genome, resulted in prediction of nearly 300 gene families that were over-represented around the known defense genes. Among these, genes that tend to form conserved clusters were assumed to represent candidate defense systems, and some were experimentally investigated. This resulted in validation of a dozen novel types of antiviral systems $[21,22]$. Even though in recent years our understanding of the abundance of defense systems types was significantly expanded, it can be expected that we have unraveled only a small proportion of their real diversity, as vast majority of the genomic data is considered as a "dark matter" and defense islands consisting solely from genes of unknown function are not-detectable by the current methods [23]. Further improvement of the algorithms, like the use of more elaborate protein domains classification, or application of deep learning approaches already proved useful in gene predictions [24-26] should promote further advancement in the field. At the same time, discoveries of novel systems pose a challenge of their functional and biochemical characterization, as current-

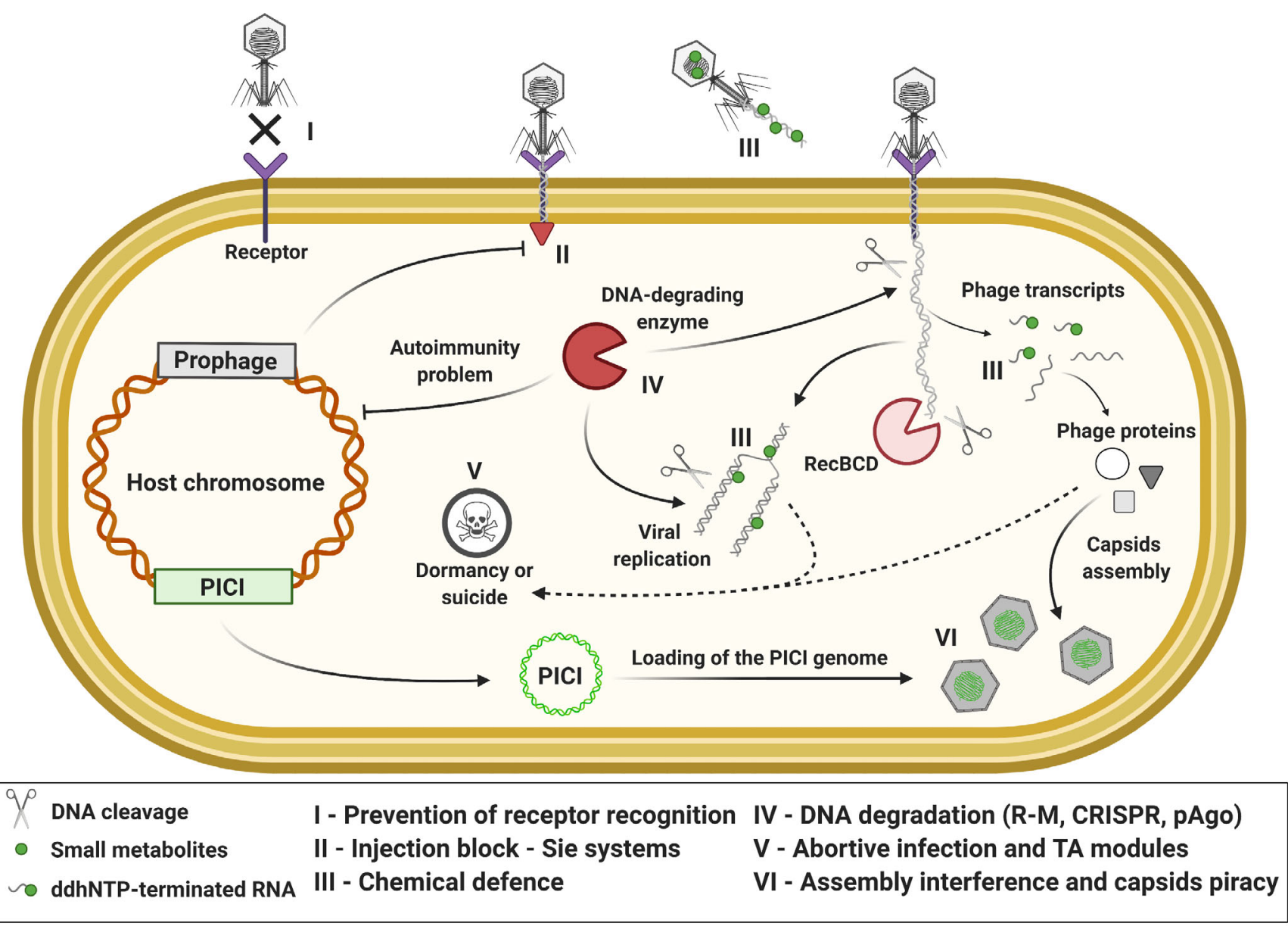

Fig. 1. General outline of the microbial defense strategies targeting different stages of the viral life cycle. (Colored versions of Figs. 1-6 are available in online version of the article and can be accessed at: https://www.springer.com/journal/10541) 
ly mechanisms of protection for most are poorly understood.

The outline of defensive strategies targeting different stages of the viral life cycle is presented in Fig. 1. Microbial resistance to phage infection could be associated with activity of specific immunity systems, whose main function is to inhibit foreign genetic material propagation, or with mutations and phase variation in the host genes that are required for productive viral infection. Phage resistance also could be associated with small molecules [27], or with activity of mobile genetic elements interfering with viral infection, like PLE (phageinducible island-like element) and PICI (phageinducible chromosomal islands), that in a sense can be considered as parasites of parasites [28, 29]. Immunity systems often rely on the recognition of specific sites in the invading nucleic acid or sense phage infection in other way to initiate the inhibitory response. To avoid self-toxicity a self-versus non-self-discrimination mechanism should be employed by these systems. They can be further classified into innate immunity [including different types of restriction-modification (R-M), bacteriophage exclusion (BREX), defense island systems associated with restriction-modification (DISARM), toxinantitoxin (TA), abortive infection (Abi), and plethora of less studied systems] and adaptive immunity mediated by clustered regularly interspaced repeats (CRISPR) and CRISPR-associated proteins (CRISPR-Cas). Online databases of the prokaryotic immunity systems include REBASE, collection of known R-M systems [30], TASmania that is specialized on TA systems [31], CRISPRminer and CRISPRCasdb for CRISPR-Cas systems [32, 33] and PADS that contains annotation of genes associated with different types of defenses [34]. Taxonomic distribution of the protein domains known to be involved in defense also can be viewed in AnnoTree [35].

Since the phage genomes encode only limited number of genes, most phages rely on their hosts for transcription and translation [36], and often sequester host proteins as cofactors, like in the case of thioredoxin that is required for the T7 DNA-polymerase activity [37]. Multiple studies revealed importance of the host genes for phage infection using the KEIO Escherichia coli singlegene knockouts collection, dCas9 inhibition of specific genes, and transposon insertion mutagenesis [38-44]. Mutations in the non-essential genes that are required for phage propagation is a common way for acquiring resistance, first described in classical experiments of Luria and Delbruck [45].

For every known microbial defense strategy phages evolved means for counter-defense, and thus it is only a matter of time before phage-encoded inhibitors of novel defense systems will be described [25, 26, 46]. It was proposed that similar to the defense islands, anti-defense genes tend to form clusters in phage genomes or mobile genetic elements. Existence of such anti-defense islands should promote discovery of novel host defense inhibitors [47]. Viral counter-defense systems are beyond the scope of the current paper, and this subject can be further explored in other reviews [48-50].

First part of the current review will cover microbial strategies that allow to avoid recognition by phages, innate immunity mechanisms blocking early stages of infection, and systems that rely on DNA modification for self vs non-self-discrimination. Second part will be focused on the adaptive immunity systems and defenses activated at the late stages of infection.

\section{THE SIMPLEST WAY OF PROTECTION - TO AVOID RECOGNITION}

Phage infection is initiated upon recognition of specific receptors on the surface of the cell by the phage receptor binding proteins (RBP). Different types of surface molecules can be exploited by phages as receptors, including pili and flagella, proteins, lipopolysaccharides (LPS) or carbohydrates. Interaction between the phage RBPs and the host receptor can be considered as a limiting stage in infection, responsible, at least partially, for determination of the range of susceptible hosts [51-53]. Prokaryotes employ receptors masking, modification and mutation, or production of decoys to avoid recognition by phages (Fig. 2).

Role of extracellular matrix (ECM) and outer membrane vesicles (OMV). Many bacteria are capable of secreting high-molecular weight polymers, and spatially structured communities of cells surrounded by ECM form biofilms [54, 55]. While the details of phage-host interactions in biofilms are not yet fully understood [56], it was shown that the biofilm communities tend to be more resistant to viral predation, and the increased phage pressure might even enhance formation of biofilms, wherein surface receptors are less accessible $[57,58]$. Another benefit of spatial organization is that only the surface layer of cells is exposed to phages in the environment. Often cells in this layer are metabolically inactive and thus do not allow phage reproduction, while reducing the chances of attack on underlying cells [59]. Components of ECM also may perform a function of decoys or "sinks" that adsorb and immobilize phages before they can reach the cell surface [60, 61]. It was shown that curli - proteinaceous components of ECM are associated with increased phage resistance in $E$. coli biofilms, while secretion of alginate exopolysaccharide protects Pseudomonas fluorescens [62, 63]. Polysaccharide capsule is another way to prevent phage adsorption [64], for example, overproduction of colanic acid is associated with the resistance to different phages in Escherichia, and mucoid cells with gain-of-function mutations in the RCS signaling pathway controlling this 


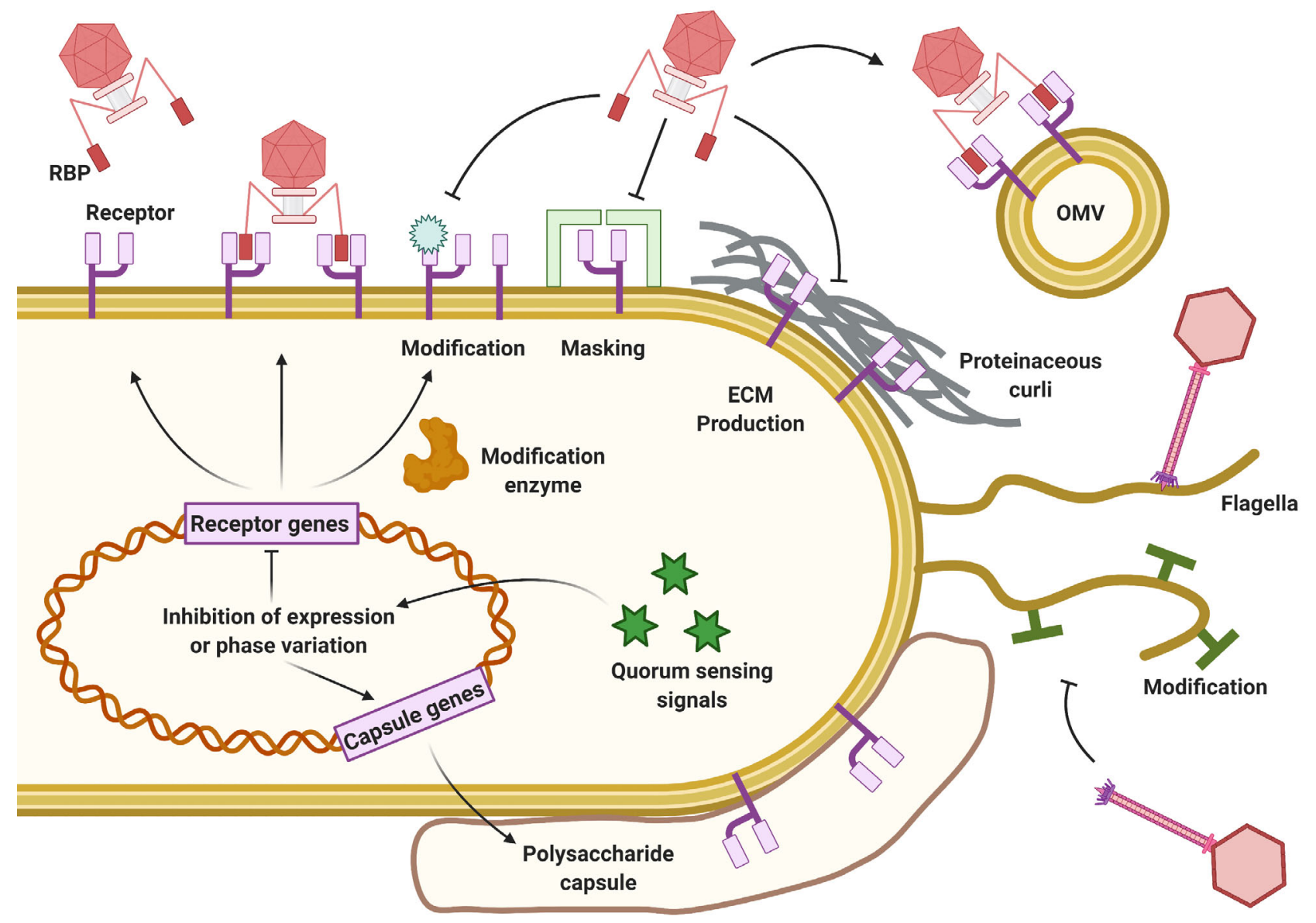

Fig. 2. Microbial strategies allowing prevention of recognition by phages.

function could be selected upon phage infection [44, 65]. The role of decoys was also shown for the extracellular vesicles produced by Vibrio and Escherichia: such vesicles containing surface receptors can adsorb phages lowering their titer in the environment $[66,67]$. On the other hand, it was demonstrated that the receptor-carrying vesicles can be incorporated into the membrane of otherwise non-susceptible Bacillus cells making them sensitive to infection [68].

Receptors alterations. Phage adsorption often can be considered as a two-stage process, where the first stage involves reversible binding to surface-exposed structures (i.e., phage T5 binding to the E. coli LPS O-antigen, or phage SSP1 binding to the B. subtilis cell wall teichoic acid), followed by irreversible attachment to a secondary receptor (i.e., FhuA and YueB proteins in the case of T5 and SSP1, respectively) [51]. Alteration of the primary and secondary surface receptors is a common way for acquiring phage resistance [69]. Even point mutations in the protein receptors genes can affect efficiency of the interaction with phage's RBPs, as was shown, for example, for the phage $T 5$ receptor FhuA or phage $\lambda$ receptor LamB [70, 71]. Mutations affecting biosynthetic path- ways responsible for the synthesis of cell wall components (Gram-negative bacteria LPS or Gram-positive bacteria teichoic acid) can lead to the alteration in the structure of these molecules, and thus affect recognition by phages targeting these receptors [72, 73]. Bacterial extracellular suprastructures also can serve as phage receptors, and mutations in the genes involved in pili or flagella formation are known to provide defense against phages [74, 75].

Receptor mutations can be hardly considered as a bona fide defense strategy, as phage infection only selects for the pre-existing resistant cells within the population. However, specific mechanisms that control receptors accessibility do exist. Bacterial surface molecules are involved in important cellular processes, including motility and nutrients transport, and their mutations can be associated with fitness costs. Thus, phase variation (reversible switching of gene expression) or masking of receptors can be a safer long-term strategy [76, 77]. Masking involves synthesis of molecules that bind to the host receptors and physically block interaction with the phage RBPs, like in the case of the TraT protein binding to the OmpA receptor in E. coli [78]. Temporal chemical 
modifications of receptors also prevent their recognition: examples include pilus glycosylation in $P$. aeruginosa or O-antigen glucosylation in Salmonella enterica $[79,80]$. Transcriptomic studies demonstrated that alteration of receptors can represent a part of the stress response, like in the case of Lactococcus lactis, wherein phage infection activates genes responsible for the cell wall D-alanylation [81]. Downregulation of the receptors expression through phase variation can be achieved by recombination or predisposed alterations in the promoter regions $[82,83]$, while mutations in the specific hot-spot loci within genes can lead to frameshifting and production of truncated proteins [84]. Multiple inversion systems, known as shufflons, also can be potentially involved in the regulation of receptors expression [85], as in the case of the PilV protein from $E$. coli IncI plasmids, where one out of seven C-terminal region variants can be selected for expression [86]. The common gut symbiont Bacteroides thethaiotaamicron was shown to employ phase variation in at least 19 loci, controlling production of different capsule types and S-layer proteins expression [87]. Phase variation permits co-existence of microbial sub-populations expressing different gene variants, allowing to hedge the risks of phage infection and effects of environmental factors.

Archaeal cell wall structure is very different from that of bacteria, and attachment of the archaeal viruses to the surface of their hosts is poorly understood [88]. Recently, the first structure-based adsorption model was provided for the archaeophage STIV binding to the pili-like structure of Sulfolobus cells [89]. Mutations in the genes associated with the surface molecules in Sulfolobus were shown to provide resistance to SIRV2 infection [90]. Despite a lack of data, one can expect that mechanisms similar to those described for bacterial cells also prevent adsorption of archaeal viruses to their hosts.

\section{SMALL MOLECULES AND PHAGE DEFENSE}

Direct role in defense. A plethora of early phage biology studies investigated the effects of chemicals on the efficiency of viral infection [91-93]. It was demonstrated that certain compounds, including bacteria-synthesized antibiotics, may affect production of phage progeny at concentrations subinhibitory for bacterial growth [9496]. Likewise, DNA-staining dyes and intercalating agents (e.g., propidium iodide or doxorubicin) can inactivate phage particles [97]. Yet, only recently the involvement of small molecules produced by bacteria in phage defense had been re-evaluated [27]. High-throughput screening of chemical libraries identified molecules that were able to interfere with phage $\lambda$ infection in $E$. coli without affecting bacterial growth. The anti-phage activity was shown in a biologically relevant context: addition of the spent medium collected after the growth of dox- orubicin- and daunorubicin-producing strain of Streptomyces peucetius was able to inhibit infection in the phage-sensitive strain of $S$. coelicolor. The authors further demonstrated that $\sim 1 / 3$ of tested Streptomyces extracts had anti-phage activity against natural isolates of actinophages, which suggested that chemical defense is a widespread strategy. In most of the extracts anthracyclines or other DNA intercalating agents were determined as active components. Some DNA intercalating agents can inactivate phage particles before their contact with the cell by promoting non-controlled DNA ejection [98]. Yet it was shown that phage DNA can enter the cell in the presence of daunorubicin but early stages of infection were suppressed [27]. This work raises questions regarding inhibitory mechanisms of small molecules, their specificity, self-toxicity avoidance and possibility to use anti-viral metabolites as a community resource in microbial populations.

Viperins and chain termination nucleotides. Interferon-induced antiviral response of higher eukaryotes, including humans, involves synthesis of the chainterminating ribonucleotide ddhCTP, achieved through activation of the viperin enzyme [99]. Chain termination is supposed to suppress viral transcription and inhibit replication of viruses with RNA genomes [100]. Viperin genes were sporadically encountered in the genomes of Bacteria and Archaea, and a recent study demonstrated that prokaryotic viperins (pVips) provide protection against phage infection [101, 102]. In contrast to eukaryotic homologs synthesizing ddhCTP, $\mathrm{pVips}$ also producde ddhUTP and ddhGTP. Heterologous expression of various pVips in E. coli inhibited phage T7 infection and T7 RNA polymerase transcription [102]. pVips expression had no effect on the host transcription and was not toxic to cells, suggesting that viral RNA polymerases are more sensitive to ddhNTP inhibition. Intriguingly, pVips expression provided much higher level of protection against phages $\mathrm{P} 1$ and $\lambda$ that rely on the host RNA polymerase for transcription of their genes, which implied existence of additional defense mechanisms associated with viperins. $p$ Vip genes are found to be enriched within defense islands and can be accompanied by the genes of nucleotide kinases, that generateNTPs from NMPs and possibly increase the pool of NTP substrates for pVips. It has been also suggested that the genes of HicA-like RNAse or ankyrin repeat domain proteins found close to some pVip genes are involved in the phage infection sensing [102].

Regulatory role. Small metabolites also can be involved in microbial phage defense as signaling molecules or as cofactors for immunity proteins. The examples will be described later, while here we will cover the indirect role of small molecules in regulation of the defense genes expression. Quorum sensing (QS) allows to measure microbial population density and can be considered as a communication system that is based on the secretion 
of extracellular molecules [103]. High-density populations are more vulnerable to phage infections and QSmediated activation of defense barriers with increasing cell density is beneficial for survival. For example, in a selection experiment QS-proficient $P$. aeruginosa culture was shown to achieve higher levels of phage resistance compared to the QS-deficient cells [104]. Besides their role in biofilm formation [105], QS signals can regulate expression of phage receptors and immunity systems genes. For instance, $N$-acylhomoserine lactone treatment reduces amount of phage $\lambda$ receptors in E. coli [106], while in $V$. anguillarum it leads to the production of extracellular proteases and lowers the amount of the phage KVP40 receptors [107, 108]. QS regulation was shown to activate expression of the CRISPR-Cas systems components in Serratia, Pseudomonas, and other bacteria [109, 110]. To guide the lysis-lysogeny decision many phages exploit bacterial QS signals or encode their own signaling systems, like the recently described Arbitrium [111-114]. One can speculate that bacteria may intercept inter-viral communication molecules or produce their own specific signals upon phage infection for mobilization of defense barriers in the population.

\section{PHAGE GENOME ENTRY INHIBITION}

Following adsorption, phage genome is ejected from the capsid and transported into the host cell [115]. Several mechanisms block this stage of the viral life cycle [116]. As a rule, such mechanisms are encoded by prophages and underlie the phenomenon of superinfection exclusion $(\mathrm{Sie})$ - prevention of secondary infection with homoimmune phages after the primary infection (or lysogenisation) is established [117]. Membrane-associated Sie proteins can block phage DNA entry by targeting phage tape measure protein, like in the case of Streptococcus thermophilus phage TP-J 34 lipoprotein [118, 119] or E. coli phage HK97 gp15 [120, 121]. Phage T4 Sp protein is known to inhibit T4 lysozyme, required for degradation of the cell wall peptidoglycan layer in E. coli [122]. Host proteins required for phage DNA translocation are thought to be other targets for Sie, like the phage T4 Imm protein [122, 123] or mycobacteriophage Fruitloop gp52 protein that interacts with the host Wag31 and inhibits infection by the Wag31-dependent phages [124]. Sie systems with unknown targets were described for Lactococcus lactis phage Tuc2009 [125], $S$. enterica phage P22 [126], V. cholerae phage K139 [127], E. coli phage P1 [128] and P. aeruginosa B3-like phages [129]. Although Sie systems are considered primarily as a means of competition between phages [130], they provide benefits for the host and can eventually become an integral part of the chromosome, like in the case with protein DicB encoded by the cryptic prophage Qin in E. coli [131].

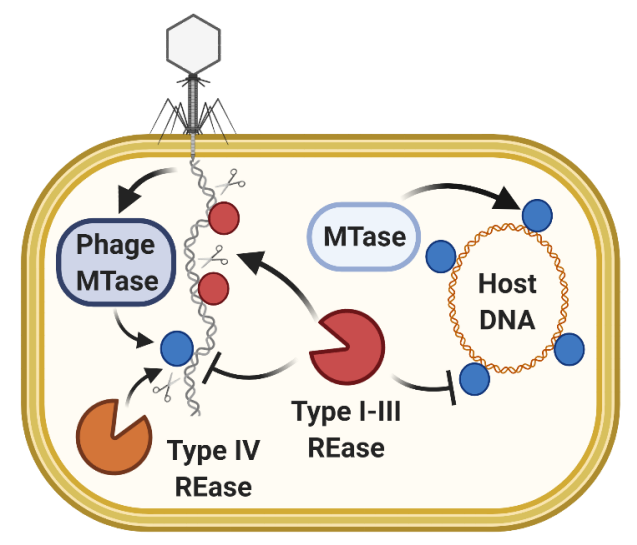

General prinicple of Type I-IV R-M systems action

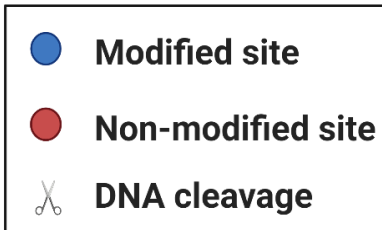

Fig. 3. Principle of classical R-M systems. MTase from the Type IIII systems modifies specific motives in the host DNA, while nonmethylated sites in the foreign DNA are cleaved by REase. Type IV REase lacks cognate MTase and cleaves DNA modified by the viral MTase.

\section{DNA MODIFICATION-BASED IMMUNITY SYSTEMS}

Once the phage genome is inside the cell it can be targeted by a variety of enzymes that cause its degradation. For example, the RecBCD nuclease/helicase complex that is also involved in host DNA repair targets free DNA ends that are exposed at the early stages of infection by dsDNA phages with linear genomes [132, 133]. Most often the function of incoming DNA degradation is performed by innate and adaptive immunity systems. Modification of the host DNA that is required for discrimination of the cell's own and foreign genetic material is a hallmark of the R-M systems. Modification module is responsible for epigenomic labeling of the host DNA, while the non-labeled phage DNA is a subject of endonucleolytic cleavage executed by the restriction module $[134,135]$. The general principle of R-M mechanism is depicted in Fig. 3. In addition to the classical R$\mathrm{M}$, there is a plethora of defense systems encoding modification module, however, their mechanisms of restriction of foreign genetic material have not yet been determined.

Classical R-M systems. R-M systems were discovered in the early 1950s while deciphering the phenomenon of host-controlled viral modification [136, 137]. They were extensively studied during the early years of molecular 
biology, culminating in wide applications and rise of the recombinant DNA technologies [138]. More than 300,000 known or putative R-M enzymes are currently listed in the REBASE and R-M systems have been found in $\sim 90 \%$ of the sequenced bacterial and archaeal genomes [30]. The functional subunits of R-M systems include methyltransferase (MTase) that transfers methyl group from the S-adenosyl methionine (SAM) donor molecule to cytosine or adenine in DNA, and cognate restriction endonuclease (REase). Some systems also encode translo- case that utilizes the energy of ATP hydrolysis for motor functions, and has a specificity subunit containing target recognition domains (TRD) that define REase and MTase sequence specificity. Based on the subunit composition, co-factors requirement, and the mode of action, R-M systems are divided into 4 types. However, this classification does not reflect their evolutionary relationship [139, 140]. Subunit composition for the modification and restriction complexes, some recognition sites, and cleavage patterns of the Type I-IV R-M systems are presented in Fig. 4.

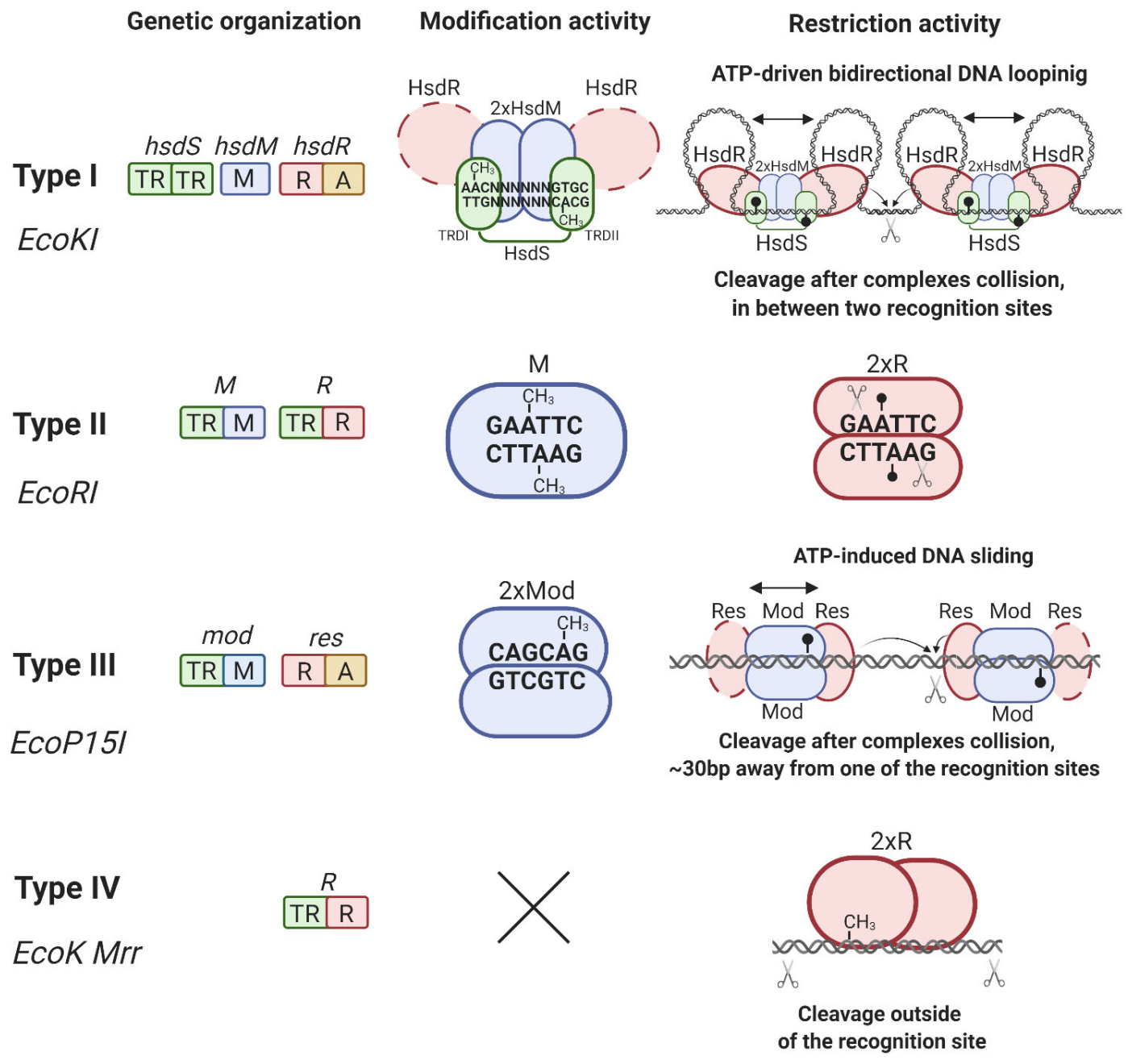

\begin{tabular}{|lllll|}
\hline $\mathbf{M}$ Methyltransferase & TR Target Recognition & $\mathrm{CH}_{3}$ Modified site & D \\
$\mathbf{R} \begin{array}{l}\text { Restriction } \\
\text { Endonuclease }\end{array}$ & A ATPse/Translocase & $\mathbf{9}$ Non-modified site & \\
\hline
\end{tabular}

Fig. 4. Functional subunits, recognition sites, composition of modification and restriction complexes for the representative members of Type I-IV R-M systems. Type II R-M usually recognize palindromic sites and both DNA strands within or in close proximity to the non-methylated sites are cleaved; Type I R-M systems modify both strands of the bipartite asymmetric DNA sites, cleavage requires interaction of two restriction complexes bound to non-methylated sites, achieved through ATP-dependent DNA looping, and occurs at non-fixed position in between; Type III R-M systems modify only one strand of the asymmetric recognition sites, cleavage occurs at a fixed position from one recognition site, when the restriction complex bound to the non-methylated site interacts with other complex that was activated by recognition of the nearby non-methylated site in the inverted repeat orientation; Type IV R-M systems lack modification module and cleave DNA after recognition of the modified sites. Dashed line indicate that the subunit could be dispensable for the depicted activity. 
Type II R-M is the most studied group. Systems of this type normally comprise separate MTase and REase proteins. MTase is monomeric, while REase acts as a homodimer. Typically, both cognate enzymes recognize the same specific 4-8 bp long palindromic DNA site. DNA cleavage occurs at both DNA strands at a fixed position within or in close proximity to the non-methylated recognition site and is dependent on the presence of divalent cations, in most cases $\mathrm{Mg}^{2+}$ [141, 142]. MTase efficiently methylates non-methylated sites and hemimethylated sites that are produced after DNA replication of fully methylated DNA, while REase has low binding affinity to the methylated and hemi-methylated sites [143]. In addition to the described simple mode of action characteristic for the IIP subtype, enzymes of other subtypes could display unusual features [139]. For example, the Type IIA, IIS, and IIL enzymes recognize asymmetric sequences; the REase and MTase polypeptides in the Type IIC and IIL are fused; while the Type IIE and IIF REases require binding to two sites for cleavage. The IIL and IIG subtypes enzymes (e.g., MmeI and Eco571) recognize asymmetric sites that are methylated only at one DNA strand [144, 145]. The second strand of the Eco571 sites is methylated by an additional methyltransferase [145]. It is not clear how post-replicational cleavage of the non-methylated sites in IIL systems is avoided. Excessive REase expression is toxic to the cell, while the excess of MTase can lead to methylation of incoming phage genomes and restriction evasion. Thus, orchestrated regulation of MTase and REase genes expression should be achieved, for example, by the activity of the controller C-protein [146, 147] or by the MTase binding and/or methylation of its own promoter [148].

The type I R-M systems encode MTase (HsdM), REase (HsdR), and specificity subunit (HsdS) and the most studied example of this kind of system is EcoKI. These enzymes function as $\mathrm{HsdM}_{2}-\mathrm{HsdS}_{1}-\mathrm{HsdR}_{2}$ complexes, which can perform both restriction and methylation activities, while methylation also can be performed by the $\mathrm{HsdM}_{2}-\mathrm{HsdS}_{1}$ or $\mathrm{HsdM}_{2}-\mathrm{HsdS}_{1}-\mathrm{HsdR}_{1}$ complexes [149-151]. The bipartite DNA sites separated by a degenerate sequence ( A ACNNNNNNGTGC for EcoKI) are recognized by 2 TRD domains in the HsdS subunit, and both DNA strands of these asymmetric sites are methylated. The mechanistic model of restriction activity is quite comprehensive: after recognition of a non-methylated site by the restriction complex, the ATPase motor function of the HsdR subunit is activated and the complex pulls on the bound DNA in both directions creating loops [152]. Translocation consumes about 3 ATP molecules per nucleotide [153]. Cleavage occurs when 2 restriction complexes anchored on the different sites collide or when a roadblock (a replication fork or a supercoiled region) is encountered by one of the complexes [154]. Positions of the DNA cleavage are not fixed and it usually occurs between 2 neighboring recognition sites [155]. SAM is required not only as a donor of methyl groups but also as a cofactor for the restriction complex. Enzymes of the Type ISP subclass represent single polypeptide combining methylation and restriction activities, and methylate only one DNA strand $[156,157]$. To lower the risks of the host DNA damage, activity of the Type I complexes can be additionally controlled, for example, by the ClpXP-mediated proteolytic cleavage of the HsdR subunit, the phenomenon that is known as restriction alleviation $[158,159]$. The type I enzymes are known to alter sequence specificity through phase variation of their TRD domains [160].

The type III R-M systems in many aspects are similar to the Type I [161]. They function as multiprotein complexes consisting of Mod and Res subunits. DNA modification is performed by the $\operatorname{Mod}_{2}$ homodimer, while $\mathrm{Res}_{2}-\mathrm{Mod}_{2}$ or $\operatorname{Res}_{1}-\mathrm{Mod}_{2}$ complexes serve as ATPand SAM-dependent REases [162, 163]. The type III enzymes recognize short non-palindromic DNA sequences and methylate only one DNA strand. Thus, similar to the Type ISP enzymes, half of their hemimethylated sites become non-methylated after replication. To ensure that cell's own DNA is not a subject of restriction, two sites in reverse (head-to-head or tail to tail) orientation are required for cleavage, e.g., when two non-methylated neighboring sites are located on different DNA strands - a situation, which is not normally encountered in the host DNA [164, 165]. Recognition of the non-methylated DNA site activates translocase activity of the Res subunit, but in contrast to the Type I enzymes, it consumes much less ATP and instead of bidirectional looping triggers one-dimensional diffusion along the DNA [166, 167]. Cleavage occurs at a fixed position from one of the recognition sites, when the activated restriction complex interacts with another complex bound to the non-methylated site. Expression of the Mod subunit can be regulated through phase variation [168].

To avoid cleavage by the host REases, phages can incorporate modified bases into their genome [169] and the Type IV R-M systems evolved in response to specifically target modified DNA [170,171]. This is a divergent and poorly studied group of the solitary REase proteins that lack cognate Mtase. The subtype IIM enzymes also recognize methylated bases and are considered as Type IV by some authors [171]. The type IV REase usually have broad sequence specificity and can target methylcytosines (McrA), methyladenines (Mrr), or phosphorothioated DNA (ScoMcrA) [172-174]. Some enzymes of this group require ATP or GTP hydrolysis and more than one site for cleavage (McrBC or SauUSI) [175, 176]. Abundance of these proteins and their ecological importance is likely underestimated.

In addition to their role in phage resistance and HGT control, R-M systems influence other biological processes [177]. For example, MTase genes are often 
found without the cognate REase genes and such orphan enzymes are thought to be involved in regulation of gene expression or replication. The best characterized examples include the Dam MTase in E. coli and CcrM in Caulobacter crescentus [178, 179]. The R-M systems may be considered as selfish TA elements, since the loss of an MTase gene can lead to post-segregational killing associated with DNA damage elicited by the REase [180]. The evolutionary and ecological roles of R-M systems have been addressed in several reviews [76, 181-183].

Phage growth limitation (Pgl) system. Pgl could represent a unique example of the reverse mode of action to the R-M systems, where the modified DNA is restricted, but unlike in the case of the Type IV R-M systems, modification of the phage genome is carried out by the host defense system itself. The Pgl defense was first described during isolation of the $\varphi \mathrm{C} 31$ phage infecting Streptomyces coelicolor A(3)2 [184] and later it was shown that the phage progeny was released from the Pgl+ cells after the first round of infection but subsequent rounds of infection of the host were restricted [185]. It was suggested that the initially released phages bore Pgl-specific modifications. The Pgl system has been found only in Actinomyces. It is assumed that such altruistic behavior could be afforded by multicellular bacteria that sacrifice one compartment for the protection of the whole mycelium. At the same time, Pgl mode of action might be beneficial in competition with the closely related Pgl-deficient cell types, since the $\mathrm{Pgl}+$ cells produce modified phages that are capable to target other, but not the Pgl+ hosts [186]. The Pgl phenotype has an additional benefit: in the case of classical R$M$ systems erroneous methylation of the phage genome often leads to the emergence of the protected phage progeny, which would be able to wipe out the bacterial population. In contrast, the reverse mode of action characteristic of Pgl ensures that no escaper phages can emerge in the course of infection (Fig. 5).

The Pgl system encodes 4 components: PglX - an adenine-methyltransferase, PglY - an ATPase, PglW - a protein kinase; and $\mathrm{PglZ}$ - an alkaline phosphatase a

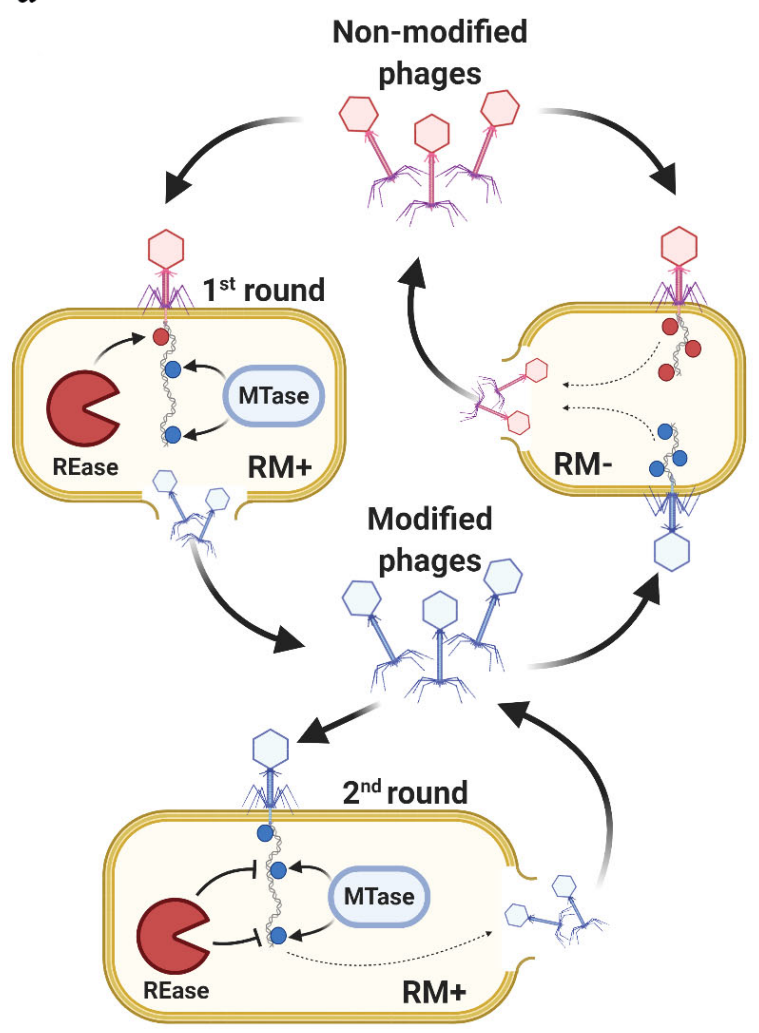

b

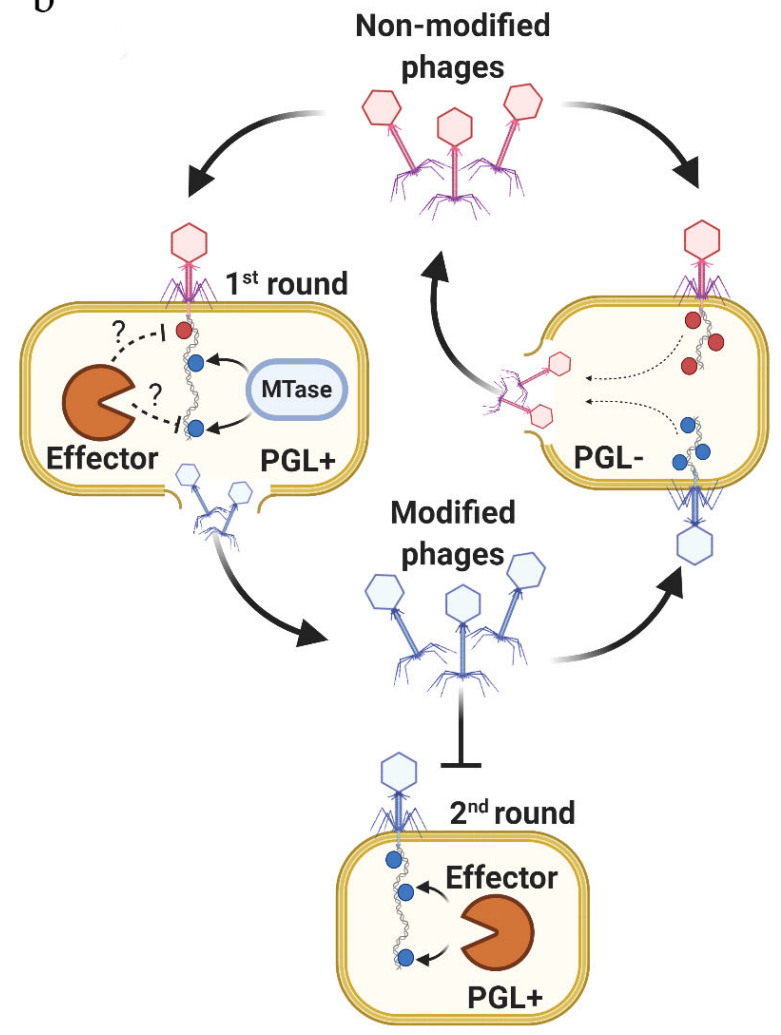

\section{Non-modified site $\bigcirc$ Modified site}

Fig. 5. a) Direct mode of R-M action: erroneous methylation of the phage DNA during infection of the cells bearing classical R-M system $(\mathrm{RM}+)$ leads to production of the phage progeny that will be able to continue efficient infection of the RM+ host. Modification can be lost only after phage passage through the R-M deficient cells (RM-). b) Reverse mode of R-M suggested for the Pgl system: after the first round of infection Pgl+ cells produce Pgl-modified phage, that is restricted in the Pgl+ cells during the second round of infection; Pgl-modified phage can efficiently infect Pgl-deficient hosts. 
(Fig. 6a) [187-189]. All four proteins are required for defense and activity of the first three components has been demonstrated in vitro [190]. Deletion of the $p g l Z$ gene is impossible in the presence of functional $\mathrm{pglX}$. Thus, it was suggested that the proteins encoded by these genes form a TA pair and that PgIX plays a critical role in restriction, when its activity is unrestrained by $\mathrm{PlgZ}$ [190]. The mechanisms of phage infection sensing by the $\mathrm{Pgl}$ system and of the restriction module functioning have not been determined yet.
BacteRiophage EXclusion systems (BREX). Global analysis of the $p g l Z$ gene distribution in the defense islands has shown that it could be found not only in Actinomyces, and also it could be often embedded in the conserved gene clusters distinct from the Pg1 [18]. It was assumed that these $p g l Z$-containing clusters represent a novel superfamily of phage defense systems denoted BREX [191]. Based on the composition of components, the BREX systems have been classified into 6 types, and $\mathrm{Pgl}$ has been assigned to the Type II BREX (Fig. 6a).

a

\section{BREX and DISARM system components}

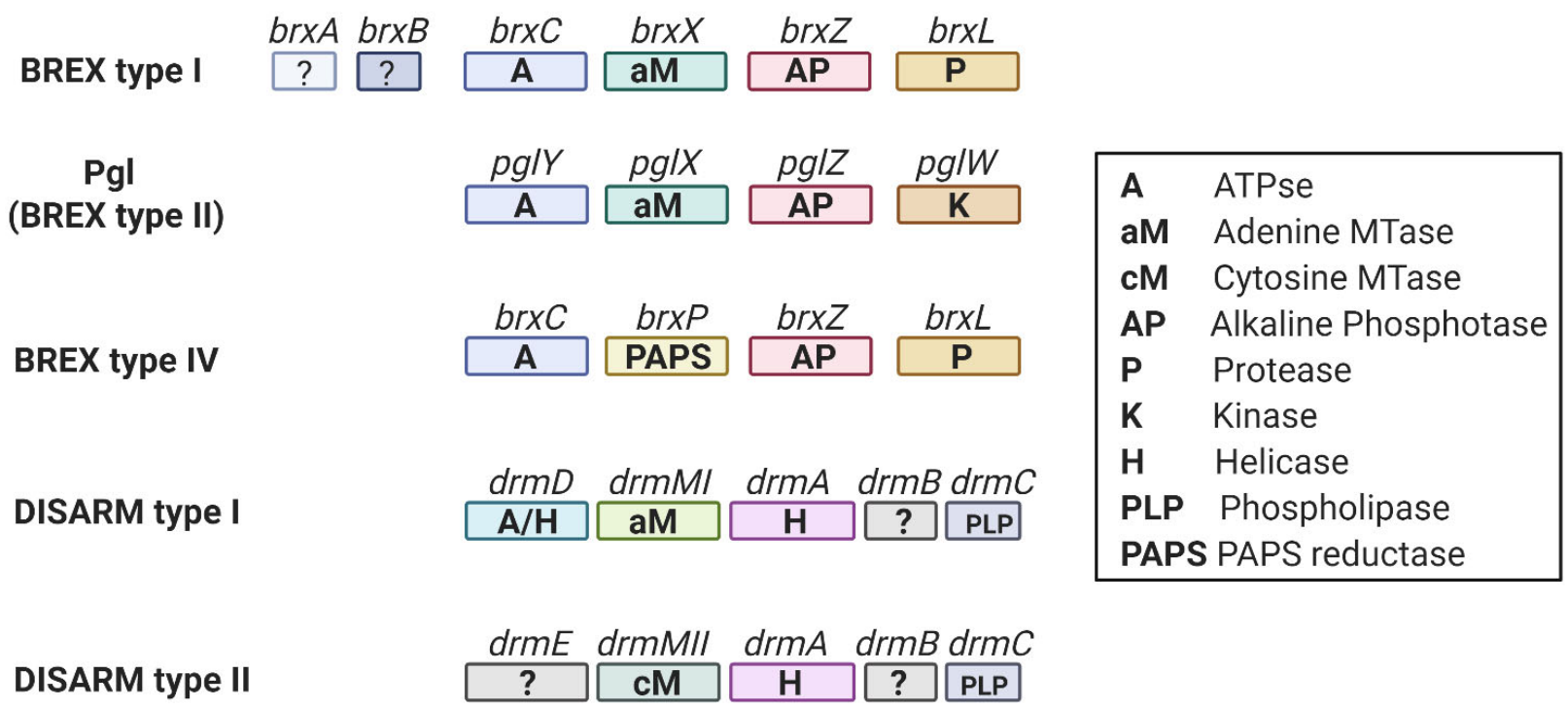

b

PT modification systems

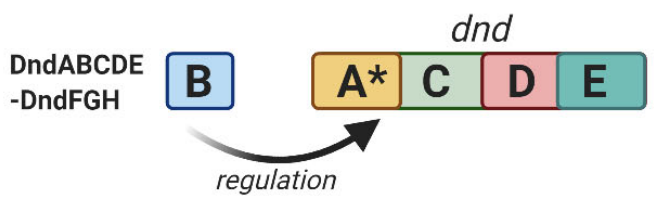

DndACDE-PbeABCD

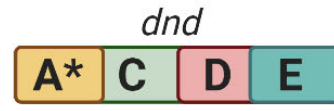

SspABCD-SspE

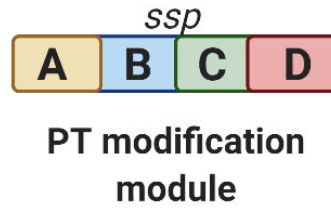

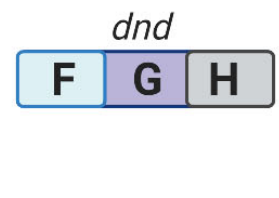
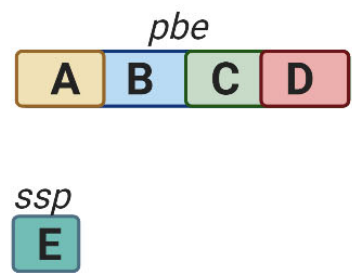
PT restriction module

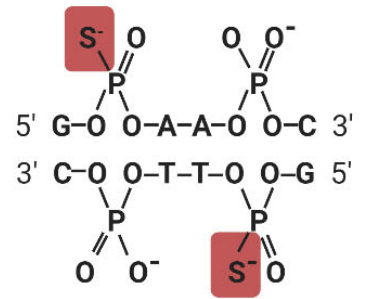

Dnd

Ssp

Fig. 6. a) Functional characteristics of subunits in different types of BREX and DISARM systems. Order of components on the scheme do not always reflect actual organisation of genes in the operons. b) PT modification-based systems and phosphorothioate modification of the DNA backbone; due to the transient nature of PT modification, only small proportion of the sites are actually modified in the genome, Dnd motifs could remain hemi-modified. 
Besides the presence of $\mathrm{PglZ}$, the common feature of all BREX systems is the presence of ATPase and methyltransferase. In the Type IV systems, the latter is replaced by a PAPS reductase, an enzyme that can be involved in DNA phosphorothioation [192]. The most prevalent is the Type I BREX and systems of this type have been experimentally investigated in B. subtilis, E. coli, and $V$. cholerae (where it has been found in the SXT conjugative elements) [191, 193, 194]. Activity of the BREX methyltransferase has also been demonstrated in Lactobacillus casei [195]. The core components of Type 1 BREX systems include BrXX (PglX), an adenine-specific methyltransferase, BrxZ (PglZ), an alkaline phosphatase, BrxC, an ATPase, BrxL, a Lon-like protease, and small protein of unknown function BrxB. These predicted activities have not been verified in vitro and some large domains of the BREX proteins have not been assigned a function yet. Additional small proteins that are presumably playing a regulatory role or are required to confer protection from the specific phages also could be present (i.e., BrxA) [191, 193].

Similar to the classical R-M systems, it was shown that the BREX systems methylate cell's own DNA, and presence of the BREX-specific modifications in the phage genome allow to overcome the defense [191, 193]. BREX sites are non-palindromic and are methylated only at one strand, which, similar to the Type III and ISP R$\mathrm{M}$ systems, might imply the requirement of multiple sites and their specific orientation for restriction. BREX acts at the early stages of phage infection and accumulation of the phage progeny DNA inside the BREX+ cells is prevented. Yet, the mechanisms of restriction remain unknown. The $E$. coli BREX defense is suppressed by the phage T7 DNA mimic protein Ocr [46], which is a wellknown Type I R-M systems inhibitor [151, 196, 197]. This result seems to suggest common mechanistic features between the BREX and multisubunit complexes of $\mathrm{R}-\mathrm{M}$ systems.

Defense Island System Associated with RestrictionModification (DISARM) systems. Following the discovery of BREX, mining of the conserved gene clusters in the defense islands resulted in prediction of another novel system - DISARM [198]. Antiviral activity was demonstrated for the DISARM system from $B$. paralicheniformis. It comprises five components: the DrmA helicase, the DrmB protein with unknown function domain DUF1998, DrmC, containing a phospholipase D (PLD) domain, DrmE, and cytosine-specific methyltransferase DrmMII [198]. This composition is typical for the class 2 DISARM, while in more abundant class 1 DrmMII is substituted with DrmMI, an adenine-methyltransferase, and DrmE - with DrmD, a SNF-2 like helicase (Fig. 6a). The PLD domains can be involved in catalytic activity of nucleases [199]. Yet, surprisingly, DrmC was shown to be dispensable for the DISARM-mediated defense against phages. DrmMII alone can methylate symmetric
(CEWGG) sites in the host DNA and deletion of the methyltransferase gene in the presence of the full DISARM cluster is toxic to cells. Yet, in contrast to the classical R-M phenotype, phage $\varphi 3$ T with the DISARM-specific methylation was unable to infect DISARM+ cells, suggesting that methylation is necessary but not sufficient to avoid restriction [198]. Similar to BREX, DISARM does not affect phage adsorption and inhibits early stages of infection by an unknown mechanism.

7-Deazapurine in DNA (DPD) systems. Besides DNA methylation, 7-deazaguanine based modifications also can be coupled with the R-M like defense systems [200]. Multiple enzymes are involved in generation of 7deazaguanine, which usually serves as a precursor of the modified bases in tRNA. Some prokaryotes encode additional biosynthetic gene clusters responsible for introduction of 7-deazaguanine in DNA [200]. Such DPD systems (from 7-deazapurine in DNA) can consist of up to 10 components (DpdA-K) [200, 201]. The R-M-like activity of the DPD system was suggested based on inhibition of transformation of the non-modified plasmid into the cells of Salmonella Montevideo carrying a $d p d$ cluster [200]. Activity of the DPD system against phage infection had not been demonstrated so far, and possible restriction mechanism remains unclear. Auxiliary DPD components include helicases, ParB-like NTPase, and PLD nuclease, which may be involved in the restriction of unmodified DNA. Interestingly, similar 7-deazaguanine modification clusters have been identified in some viral genomes (e.g., in phages 9g or Cajan), where modification was shown to protect phage DNA against a wide spectrum of REases [202, 203].

Phosphorothioate (PT) modification-based systems. While modifications discussed so far affected only nucleobases, the DNA sugar-phosphate backbone also can be subjected to modification. Replacement of a non-bridging oxygen with a sulfur atom that leads to formation of the phosphorothioate internucleotide linkage - PT modification - could be associated with different defense systems in Bacteria and Archaea [204-206]. These systems are summarized in Fig. 6 b.

The PT modification occurs as a result of the activity of the system of $d n d A B C D E$ genes (Dnd is a phenotype associated with DNA degradation), which encode the DndA cysteine desulfurase, the DndC PAPS reductase, the DndD ATPase/nicking endonuclease, and a small protein DndE that binds nicked DNA, while DndB regulates transcription of the $d n d B C D E$ operon and determines proportion of the PT-modified sites in the genome [204, 207-209]. Not all stages of the biochemical pathway involved in PT modification have been determined but it is known that cysteine serves as a donor of the sulfur atom that is transferred to DndC and next incorporated in an energy-dependent manner into the DNA that was preliminary nicked at specific sites by DndD [192, 210, 211]. Recently, it was shown that the $d n d$ genes could also be 
involved in the PT modification of RNA [212]. On its own, the PT modification is thought to be involved in the maintenance of the redox homeostasis and control of gene expression [213], but the Dnd modification module in Bacteria is often accompanied by the $d n d F G H$ restriction gene cluster [214]. In vitro activity of the DndFGH components has not been investigated but the presence of the dndABCDE-FGH cluster in vivo inhibits transformation with the non-modified DNA, while DndFGH expression in a strain without DndABCE leads to the cleavage of cell's own DNA [214-216]. The most prominent feature of PT modification, which is quite distinct from the R-M methylation, is the fact that only a small proportion of available sites are modified and modification of each specific site is transient, which raises questions about the mechanisms of self-immunity avoidance [217, 218]. Presence of Dam methylation affects distribution of the PT-modified sites, while does not affect their overall density [219]. It was further suggested that PT modification specificity could be defined by the overall geometry of the DNA site, rather than its sequence [219].

The PT modification has also been shown in Archaea, where, instead of the $d n d F G H$, the restriction function is performed by the pbe $A B C D$ gene cluster [205]. The dndCDEA-pbeABCD from Haloterrigena jeotgali was shown to provide antiviral defense, and restriction activity was dependent on the functionally active PT modification module, which is distinct from the $d n d F G H$ behavior [205]. Accumulation of the viral DNA was not observed inside dndCDEA-pbeABCD infected cells, though its cleavage has not been demonstrated either. The pbeABCD genes can be found as solitary or adjacent to the methyltransferase genes, which implies a possibility of exchange of modules between the different defense systems [205].

Recently, another novel PT modification-based defense system has been discovered - SspABCD-SspE [206]. The sspABCD genes are not homologous to $d n d A B C D E$ but encode similar functional domains and perform PT modification of DNA, while SspE serves as a restriction component, inhibiting phage infection. In vitro, $\mathrm{SspE}$ was shown to possess an NTPase activity, which was stimulated by the presence of PT-modified sites, and non-specific nicking endonuclease activity [206]. The feature of the SspABCD system is modification of only one DNA strand within non-palindromic recognition sites.

Description of other prokaryotic defense strategies, and discussion of the interplay between different antiviral systems will be continued in the second part of the manuscript [Biochemistry (Moscow), vol. 86, Issue 4].

Acknowledgments. The authors are grateful to Anna Ershova and Andrey Letarov for critical remarks. Illustrations were prepared using BioRender.com under the paid subscription.
Funding. The work was supported by the Russian Foundation for Basic Research (projects nos. 19-1450560, 19-34-90160). AI was supported by the grant from the Russian Foundation for Basic Research (no. 19-3490160), OM was supported by the grant from the Russian Science Foundation (no. 19-74-00118).

Authors' contributions. AI composed the manuscript, AI\&OM prepared illustrations, KS revised the text.

Ethics declarations. The authors declare no conflict of interest in financial or any other sphere. This article does not contain any studies with human participants or animals performed by any of the authors.

Open access. This article is distributed under the terms of the Creative Commons Attribution 4.0 International License (http://creativecommons.org/licenses/ by/4.0/), which permits unrestricted use, distribution, and reproduction in any medium, provided you give appropriate credit to the original author(s) and the source, provide a link to the Creative Commons license, and indicate if changes were made.

\section{REFERENCES}

1. Clokie, M. R. J., Millard, A. D., Letarov, A. V., and Heaphy, S. (2011) Phages in nature, Bacteriophage, 1, 3145.

2. Díaz-Muñoz, S. L., and Koskella, B. (2014) Bacteriaphage interactions in natural environments, in Advances in Applied Microbiology, Elsevier, Vol. 89, pp. 135-183.

3. Batinovic, S., Wassef, F., Knowler, S. A., Rice, D. T. F., Stanton, C. R., et al. (2019) Bacteriophages in natural and artificial environments, Pathogens, 8, 100.

4. Wommack, K. E., and Colwell, R. R. (2000) Virioplankton: viruses in aquatic ecosystems, Microbiol. Mol. Biol. Rev., 64, 69-114.

5. Parikka, K. J., Le Romancer, M., Wauters, N., and Jacquet, S. (2017) Deciphering the virus-to-prokaryote ratio (VPR): insights into virus-host relationships in a variety of ecosystems, Biol. Rev., 92, 1081-1100.

6. Rodriguez-Valera, F., Martin-Cuadrado, A.-B., Rodriguez-Brito, B., Pasic, L., Thingstad, T. F., et al. (2009) Explaining microbial population genomics through phage predation, Nat. Rev. Microbiol., 7, 828-36, doi: $10.1038 / \mathrm{nrmicro} 2235$.

7. Breitbart, M., Bonnain, C., Malki, K., and Sawaya, N. A. (2018) Phage puppet masters of the marine microbial realm, Nat. Microbiol., 3, 754-766.

8. Brüssow, H., Canchaya, C., and Hardt, W.-D. (2004) Phages and the evolution of bacterial pathogens: from genomic rearrangements to lysogenic conversion, Microbiol. Mol. Biol. Rev., 68, 560-602.

9. Chiang, Y. N., Penadés, J. R., and Chen, J. (2019) Genetic transduction by phages and chromosomal islands: the new and noncanonical, PLoS Pathog., 15, e1007878.

10. Lang, A. S., Westbye, A. B., and Beatty, J. T. (2017) The distribution, evolution, and roles of gene transfer agents in prokaryotic genetic exchange, Annu. Rev. Virol., 4, 87-104. 
11. Keen, E. C., Bliskovsky, V. V, Malagon, F., Baker, J. D., Prince, J. S., et al. (2017) Novel "superspreader" bacteriophages promote horizontal gene transfer by transformation, MBio, 8, e02115-16.

12. Koonin, E. V., Wolf, Y. I., and Katsnelson, M. I. (2017) Inevitability of the emergence and persistence of genetic parasites caused by evolutionary instability of parasite-free states, Biol. Direct, 12, 1-12.

13. Szathmáry, E., and Demeter, L. (1987) Group selection of early replicators and the origin of life, J. Theor. Biol., 128, 463-486.

14. Krupovic, M., Dolja, V. V., and Koonin, E. V. (2019) Origin of viruses: primordial replicators recruiting capsids from hosts, Nat. Rev. Microbiol., 17, 449-458.

15. Koonin, E. V., Makarova, K. S., and Wolf, Y. I. (2017) Evolutionary genomics of defense systems in archaea and bacteria, Annu. Rev. Microbiol., 71, 233-261.

16. Galperin, M. Y., and Koonin, E. V (2000) Who's your neighbor? New computational approaches for functional genomics, Nat. Biotechnol., 18, 609-613.

17. Shmakov, S. A., Faure, G., Makarova, K. S., Wolf, Y. I., Severinov, K. V., and Koonin, E. V. (2019) Systematic prediction of functionally linked genes in bacterial and archaeal genomes, Nat. Protoc., 14, 3013-3031.

18. Makarova, K. S., Wolf, Y. I., Snir, S., and Koonin, E. V (2011) Defense islands in bacterial and archaeal genomes and prediction of novel defense systems, J. Bacteriol., 193, 6039-56.

19. Oliveira, P. H., Touchon, M., and Rocha, E. P. C. (2014) The interplay of restriction-modification systems with mobile genetic elements and their prokaryotic hosts, Nucleic Acids Res., 42, 10618-10631.

20. Koonin, E. V., Makarova, K. S., Wolf, Y. I., and Krupovic, M. (2020) Evolutionary entanglement of mobile genetic elements and host defense systems: guns for hire, Nat. Rev. Genet., 21, 119-131.

21. Doron, S., Melamed, S., Ofir, G., Leavitt, A., Lopatina, A., et al. (2018) Systematic discovery of antiphage defense systems in the microbial pangenome, Science, 359, eaar4120.

22. Gao, L., Altae-Tran, H., Böhning, F., Makarova, K. S., Segel, M., et al. (2020) Diverse enzymatic activities mediate antiviral immunity in prokaryotes, Science, 369, 1077-1084.

23. Makarova, K. S., Wolf, Y. I., and Koonin, E. V. (2019) Towards functional characterization of archaeal genomic dark matter, Biochem. Soc. Trans., 47, 389-398.

24. Eraslan, G., Avsec, ., Gagneur, J., and Theis, F. J. (2019) Deep learning: new computational modelling techniques for genomics, Nat. Rev. Genet., 20, 389-403.

25. Eitzinger, S., Asif, A., Watters, K. E., Iavarone, A. T., Knott, G. J., et al. (2020) Machine learning predicts new anti-CRISPR proteins, Nucleic Acids Res., 48, 4698-4708.

26. Gussow, A. B., Park, A. E., Borges, A. L., Shmakov, S. A., Makarova, K. S., et al. (2020) Machine-learning approach expands the repertoire of anti-CRISPR protein families, Nat. Commun., 11, 1-12.

27. Kronheim, S., Daniel-Ivad, M., Duan, Z., Hwang, S., Wong, A. I., et al. (2018) A chemical defense against phage infection, Nature, 564, 283-286.

28. Fillol-Salom, A., Miguel-Romero, L., Marina, A., Chen, J., and Penadés, J. R. (2020) Beyond the CRISPRCas safeguard: PICI-encoded innate immune systems pro- tect bacteria from bacteriophage predation, Curr. Opin. Microbiol., 56, 52-58.

29. O'Hara, B. J., Barth, Z. K., McKitterick, A. C., and Seed, K. D. (2017) A highly specific phage defense system is a conserved feature of the Vibrio cholerae mobilome, PLoS Genet., 13, 1-17.

30. Roberts, R. J., Vincze, T., Posfai, J., and Macelis, D. (2015) REBASE - a database for DNA restriction and modification: enzymes, genes and genomes, Nucleic Acids Res., 43, D298-D299.

31. Akarsu, H., Bordes, P., Mansour, M., Bigot, D.-J., Genevaux, P., and Falquet, L. (2019) TASmania: a bacterial toxin-antitoxin systems database, PLOS Comput. Biol., 15, e1006946.

32. Zhang, F., Zhao, S., Ren, C., Zhu, Y., Zhou, H., et al. (2018) CRISPRminer is a knowledge base for exploring CRISPR-Cas systems in microbe and phage interactions, Commun. Biol., 1, 1-5.

33. Pourcel, C., Touchon, M., Villeriot, N., Vernadet, J.-P., Couvin, D., et al. (2020) CRISPRCasdb a successor of CRISPRdb containing CRISPR arrays and cas genes from complete genome sequences, and tools to download and query lists of repeats and spacers, Nucleic Acids Res., 48, D535-D544.

34. Zhang, Y., Zhang, Z., Zhang, H., Zhao, Y., Zhang, Z., and Xiao, J. (2020) PADS Arsenal: a database of prokaryotic defense systems related genes, Nucleic Acids Res., 48, D590-D598.

35. Mendler, K., Chen, H., Parks, D. H., Lobb, B., Hug, L. A., and Doxey, A. C. (2019) Annotree: visualization and exploration of a functionally annotated microbial tree of life, Nucleic Acids Res., 47, 4442-4448.

36. Howard-Varona, C., Lindback, M. M., Bastien, G. E., Solonenko, N., Zayed, A. A., et al. (2020) Phage-specific metabolic reprogramming of virocells, ISME J., 14, 881895.

37. Ghosh, S., Hamdan, S. M., Cook, T. E., and Richardson, C. C. (2008) Interactions of Escherichia coli thioredoxin, the processivity factor, with bacteriophage T7 DNA polymerase and helicase, J. Biol. Chem., 283, 32077-32084.

38. Qimron, U., Marintcheva, B., Tabor, S., and Richardson, C. C. (2006) Genomewide screens for Escherichia coli genes affecting growth of T7 bacteriophage, Proc. Natl. Acad. Sci. USA, 103, 19039-19044.

39. Maynard, N. D., Birch, E. W., Sanghvi, J. C., Chen, L., Gutschow, M. V., and Covert, M. W. (2010) A forwardgenetic screen and dynamic analysis of lambda phage hostdependencies reveals an extensive interaction network and a new anti-viral strategy, PLoS Genet., 6, e1001017.

40. Bohm, K., Porwollik, S., Chu, W., Dover, J. A., Gilcrease, E. B., et al. (2018) Genes affecting progression of bacteriophage P22 infection in Salmonella identified by transposon and single gene deletion screens, Mol. Microbiol., 108, 288305.

41. Piya, D., Lessor, L., Koehler, B., Stonecipher, A., Cahill, J., and Gill, J. J. (2020) Genome-wide screens reveal Escherichia coli genes required for growth of T1-like phage LL5 and V5-like phage LL12, Sci. Rep., 10, 1-9.

42. Rousset, F., Cui, L., Siouve, E., Becavin, C., Depardieu, F., and Bikard, D. (2018) Genome-wide CRISPR-dCas9 screens in E. coli identify essential genes and phage host factors, PLoS Genet., 14, e1007749. 
43. Kortright, K. E., Chan, B. K., and Turner, P. E. (2020) High-throughput discovery of phage receptors using transposon insertion sequencing of bacteria, Proc. Natl. Acad. Sci. USA, 117, 18670-18679.

44. Mutalik, V. K., Adler, B. A., Rishi, H. S., Piya, D., Zhong, C., et al. (2020) High-throughput mapping of the phage resistance landscape in E. coli, PLoS Biol., 18, e3000877.

45. Luria, S. E., and Delbrück, M. (1943) Mutations of bacteria from virus sensitivity to virus resistance, Genetics, $\mathbf{2 8}$, 491.

46. Isaev, A., Drobiazko, A., Sierro, N., Gordeeva, J., Yosef, I., et al. (2020) Phage T7 DNA mimic protein Ocr is a potent inhibitor of BREX defense, Nucleic Acids Res., 48, 53975406.

47. Pinilla-Redondo, R., Shehreen, S., Marino, N. D., Fagerlund, R. D., Brown, C. M., et al. (2020) Discovery of multiple anti-CRISPRs highlights anti-defense gene clustering in mobile genetic elements, Nat. Commun., 11, 1-11.

48. Samson, J. E., Magadán, A. H., Sabri, M., and Moineau, S. (2013) Revenge of the phages: defeating bacterial defenses, Nat. Rev. Microbiol., 11, 675-687.

49. Hwang, S., and Maxwell, K. L. (2019) Meet the antiCRISPRs: widespread protein inhibitors of CRISPR-Cas systems, Cris. J., 2, 23-30.

50. Hampton, H. G., Watson, B. N. J., and Fineran, P. C. (2020) The arms race between bacteria and their phage foes, Nature, 577, 327-336.

51. Bertozzi Silva, J., Storms, Z., and Sauvageau, D. (2016) Host receptors for bacteriophage adsorption, FEMS Microbiol. Lett., 363, fnw002, doi: 10.1093/femsle/ fnw002.

52. Dowah, A. S. A., and Clokie, M. R. J. (2018) Review of the nature, diversity and structure of bacteriophage receptor binding proteins that target Gram-positive bacteria, Biophys. Rev., 10, 535-542.

53. Stone, E., Campbell, K., Grant, I., and McAuliffe, O. (2019) Understanding and exploiting phage-host interactions, Viruses, 11, 567.

54. Dragoš, A., and Kovács, Á. T. (2017) The peculiar functions of the bacterial extracellular matrix, Trends Microbiol., 25, 257-266.

55. Hansen, M. F., Svenningsen, S. Lo, Røder, H. L., Middelboe, M., and Burmølle, M. (2019) Big impact of the tiny: bacteriophage-bacteria interactions in biofilms, Trends Microbiol., 27, 739-752.

56. Abedon, S. T. (2017) Phage "delay" towards enhancing bacterial escape from biofilms: a more comprehensive way of viewing resistance to bacteriophages, AIMS Microbiol., 3, 186.

57. Fernández, L., Rodríguez, A., and García, P. (2018) Phage or foe: an insight into the impact of viral predation on microbial communities, ISME J., 12, 1171-1179.

58. Henriksen, K., Rørbo, N., Rybtke, M. L., Martinet, M. G., Tolker-Nielsen, T., et al. (2019) P. aeruginosa flow-cell biofilms are enhanced by repeated phage treatments but can be eradicated by phage-ciprofloxacin combination, Pathog. Dis., 77, ftz011.

59. Hosseinidoust, Z., Tufenkji, N., and van de Ven, T. G. M. (2013) Formation of biofilms under phage predation: considerations concerning a biofilm increase, Biofouling, 29, 457-468.
60. Bull, J. J., Christensen, K. A., Scott, C., Jack, B. R., Crandall, C. J., and Krone, S. M. (2018) Phage-bacterial dynamics with spatial structure: self organization around phage sinks can promote increased cell densities, Antibiotics, 7, 8 .

61. Tan, D., Dahl, A., and Middelboe, M. (2015) Vibriophages differentially influence biofilm formation by Vibrio anguillarum strains, Appl. Environ. Microbiol., 81, 4489-4497.

62. Vidakovic, L., Singh, P. K., Hartmann, R., Nadell, C. D., and Drescher, K. (2018) Dynamic biofilm architecture confers individual and collective mechanisms of viral protection, Nat. Microbiol., 3, 26-31.

63. Scanlan, P. D., and Buckling, A. (2012) Co-evolution with lytic phage selects for the mucoid phenotype of Pseudomonas fluorescens SBW25, ISME J., 6, 1148-1158.

64. Wilkinson, B. J., and Holmes, K. M. (1979) Staphylococcus aureus cell surface: capsule as a barrier to bacteriophage adsorption, Infect. Immun., 23, 549-552.

65. Kim, M. S., Kim, Y. D., Hong, S. S., Park, K., Ko, K. S., and Myung, H. (2015) Phage-encoded colanic aciddegrading enzyme permits lytic phage infection of a capsule-forming resistant mutant Escherichia coli strain, Appl. Environ. Microbiol., 81, 900-909.

66. Reyes-Robles, T., Dillard, R. S., Cairns, L. S., SilvaValenzuela, C. A., Housman, M., et al. (2018) Vibrio cholerae outer membrane vesicles inhibit bacteriophage infection, J. Bacteriol., 200, 1-9.

67. Manning, A. J., and Kuehn, M. J. (2011) Contribution of bacterial outer membrane vesicles to innate bacterial defense, BMC Microbiol., 11, 258.

68. Tzipilevich, E., Habusha, M., and Ben-Yehuda, S. (2017) Acquisition of phage sensitivity by bacteria through exchange of phage receptors, Cell, 168, 186-199.e12.

69. Betts, A., Gifford, D. R., MacLean, R. C., and King, K. C. (2016) Parasite diversity drives rapid host dynamics and evolution of resistance in a bacteria-phage system, Evolution (N.Y.), 70, 969-978.

70. Braun, V. (2009) FhuA (TonA), the career of a protein, J. Bacteriol., 191, 3431-3436.

71. Chatterjee, S., and Rothenberg, E. (2012) Interaction of bacteriophage 1 with its E. coli receptor, LamB, Viruses, 4, 3162-3178.

72. Kulikov, E. E., Golomidova, A. K., Prokhorov, N. S., Ivanov, P. A., and Letarov, A. V. (2019) High-throughput LPS profiling as a tool for revealing of bacteriophage infection strategies, Sci. Rep., 9, 1-10.

73. Moller, A. G., Lindsay, J. A., and Read, T. D. (2019) Determinants of phage host range in Staphylococcus species, Appl. Environ. Microbiol., 85, e00209-19.

74. Wright, R. C. T., Friman, V.-P., Smith, M. C. M., and Brockhurst, M. A. (2018) Cross-resistance is modular in bacteria-phage interactions, PLoS Biol., 16, e2006057.

75. Christen, M., Beusch, C., Bösch, Y., Cerletti, D., FloresTinoco, C. E., et al. (2016) Quantitative selection analysis of bacteriophage $\varphi \mathrm{CbK}$ susceptibility in Caulobacter crescentus, J. Mol. Biol., 428, 419-430.

76. Bikard, D., and Marraffini, L. A. (2012) Innate and adaptive immunity in bacteria: mechanisms of programmed genetic variation to fight bacteriophages, Curr. Opin. Immunol., 24, 15-20.

77. Van Houte, S., Buckling, A., and Westra, E. R. (2016) Evolutionary ecology of prokaryotic immune mechanisms, Microbiol. Mol. Biol. Rev., 80, 745-763. 
78. Riede, I., and Eschbach, M. L. (1986) Evidence that TraT interacts with OmpA of Escherichia coli, FEBS Lett., 205, 241-245.

79. Harvey, H., Bondy-Denomy, J., Marquis, H., Sztanko, K. M., Davidson, A. R., and Burrows, L. L. (2018) Pseudomonas aeruginosa defends against phages through type IV pilus glycosylation, Nat. Microbiol., 3, 47-52.

80. Kim, M., and Ryu, S. (2012) Spontaneous and transient defense against bacteriophage by phase-variable glucosylation of O-antigen in Salmonella enterica serovar Typhimurium, Mol. Microbiol., 86, 411-425.

81. Fallico, V., Ross, R. P., Fitzgerald, G. F., and McAuliffe, O. (2011) Genetic response to bacteriophage infection in Lactococcus lactis reveals a four-strand approach involving induction of membrane stress proteins, D-alanylation of the cell wall, maintenance of proton motive force, and energy conservation, J. Virol., 85, 12032-12042.

82. Power, P. M., Sweetman, W. A., Gallacher, N. J., Woodhall, M. R., Kumar, G. A., et al. (2009) Simple sequence repeats in Haemophilus influenzae, Infect. Genet. Evol., 9, 216-228.

83. Turkington, C. J. R., Morozov, A., Clokie, M. R. J., and Bayliss, C. D. (2019) Phage-resistant phase-variant sub-populations mediate herd immunity against bacteriophage invasion of bacterial meta-populations, Front. Microbiol., 10, 1473.

84. Seed, K. D., Faruque, S. M., Mekalanos, J. J., Calderwood, S. B., Qadri, F., and Camilli, A. (2012) Phase variable $\mathrm{O}$ antigen biosynthetic genes control expression of the major protective antigen and bacteriophage receptor in Vibrio cholerae O1, PLoS Pathog., 8, e1002917.

85. Komano, T. (1999) Shufflons: multiple inversion systems and integrons, Annu. Rev. Genet., 33, 171-191.

86. Brouwer, M. S. M., Jurburg, S. D., Harders, F., Kant, A., Mevius, D. J., et al. (2019) The shufflon of IncI1 plasmids is rearranged constantly during different growth conditions, Plasmid, 102, 51-55.

87. Porter, N. T., Hryckowian, A. J., Merrill, B. D., Fuentes, J. J., Gardner, J. O., et al. (2020) Phase-variable capsular polysaccharides and lipoproteins modify bacteriophage susceptibility in Bacteroides thetaiotaomicron, Nat. Microbiol., 5, 1170-1181.

88. Quemin, E. R. J., and Quax, T. E. F. (2015) Archaeal viruses at the cell envelope: entry and egress, Front. Microbiol., 6, 552 .

89. Hartman, R., Eilers, B. J., Bollschweiler, D., MunsonMcGee, J. H., Engelhardt, H., et al. (2019) The molecular mechanism of cellular attachment for an archaeal virus, Structure, 27, 1634-1646.

90. Deng, L., He, F., Bhoobalan-Chitty, Y., MartinezAlvarez, L., Guo, Y., and Peng, X. (2014) Unveiling cell surface and type IV secretion proteins responsible for archaeal rudivirus entry, J. Virol., 88, 10264-10268.

91. Asheshov, I. N., Strelitz, F., and Hall, E. A. (1949) Antibiotics active against bacterial viruses, Br. J. Exp. Pathol., 30, 175.

92. Cohen, S. S. (1949) Growth requirements of bacterial viruses, Bacteriol. Rev., 13, 1.

93. Putnam, F. W. (1953) Bacteriophages: nature and reproduction, in Advances in Protein Chemistry, Elsevier, Vol. 8, pp. $175-284$.

94. Neter, E. (1942) Effects of tyrothricin and actinomycin a upon bacteriophage and bacterial toxins and toxin-like substances, J. Bacteriol., 43.
95. Jones, D. (1945) The effect of antibiotic substances upon bacteriophage, J. Bacteriol., 50, 341.

96. Knezevic, P., and Sabo, V. A. (2019) Combining bacteriophages with other antibacterial agents to combat bacteria, in Phage Therapy: A Practical Approach, Springer, pp. 257293.

97. Morita, J., Tanaka, A., Komano, T., and Oki, T. (1979) Inactivation of phage $\varphi$ X174 by anthracycline antibiotics, aclacinomycin A, doxorubicin and daunorubicin, Agric. Biol. Chem., 43, 2629-2631.

98. Duan, Z. (2016) Identification and Characterization of Novel Anti-Phage Compounds Using a High Throughput Approach, Master Thesis, University of Toronto.

99. Rivera-Serrano, E. E., Gizzi, A. S., Arnold, J. J., Grove, T. L., Almo, S. C., and Cameron, C. E. (2020) Viperin reveals its true function, Annu. Rev. Virol., 7, 421-446.

100. Gizzi, A. S., Grove, T. L., Arnold, J. J., Jose, J., Jangra, R. K., et al. (2018) A naturally occurring antiviral ribonucleotide encoded by the human genome, Nature, 558, 610614.

101. Fenwick, M. K., Li, Y., Cresswell, P., Modis, Y., and Ealick, S. E. (2017) Structural studies of viperin, an antiviral radical SAM enzyme, Proc. Natl. Acad. Sci. USA, 114, 6806-6811.

102. Bernheim, A., Millman, A., Ofir, G., Meitav, G., Avraham, C., et al. (2021) Prokaryotic viperins produce diverse antiviral molecules, Nature, 589, 120-124.

103. Ng, W.-L., and Bassler, B. L. (2009) Bacterial quorumsensing network architectures, Annu. Rev. Genet., 43, 197222.

104. Moreau, P., Diggle, S. P., and Friman, V. (2017) Bacterial cell-to-cell signaling promotes the evolution of resistance to parasitic bacteriophages, Ecol. Evol., 7, 1936-1941.

105. Srivastava, D., and Waters, C. M. (2012) A tangled web: regulatory connections between quorum sensing and cyclic di-GMP, J. Bacteriol., 194, 4485-4493.

106. Høyland-Kroghsbo, N. M., Mærkedahl, R. B., and Svenningsen, S. Lo (2013) A quorum-sensing-induced bacteriophage defense mechanism, MBio, 4, e00362-12, doi: $10.1128 / \mathrm{mBio} .00362-12$.

107. Tan, D., Svenningsen, S. Lo, and Middelboe, M. (2015) Quorum sensing determines the choice of antiphage defense strategy in Vibrio anguillarum, MBio, 6, 1-10.

108. Castillo, D., Rørbo, N., Jørgensen, J., Lange, J., Tan, D., et al. (2019) Phage defense mechanisms and their genomic and phenotypic implications in the fish pathogen Vibrio anguillarum, FEMS Microbiol. Ecol., 95, doi: 10.1093/ femsec/fiz004.

109. Patterson, A. G., Jackson, S. A., Taylor, C., Evans, G. B., Salmond, G. P. C., et al. (2016) Quorum sensing controls adaptive immunity through the regulation of multiple CRISPR-Cas systems, Mol. Cell, 64, 1102-1108.

110. Høyland-Kroghsbo, N. M., Paczkowski, J., Mukherjee, S., Broniewski, J., Westra, E., et al. (2017) Quorum sensing controls the Pseudomonas aeruginosa CRISPR-Cas adaptive immune system, Proc. Natl. Acad. Sci. USA, 114, 131-135.

111. Silpe, J. E., and Bassler, B. L. (2019) A host-produced quorum-sensing autoinducer controls a phage lysislysogeny decision, Cell, 176, 268-280.

112. Erez, Z., Steinberger-Levy, I., Shamir, M., Doron, S., Stokar-Avihail, A., et al. (2017) Communication between 
viruses guides lysis-lysogeny decisions, Nature, 541, 488493.

113. Stokar-Avihail, A., Tal, N., Erez, Z., Lopatina, A., and Sorek, R. (2019) Widespread utilization of peptide communication in phages infecting soil and pathogenic bacteria, Cell Host Microbe, 25, 746-755.

114. Bernard, C., Li, Y., Lopez, P., and Bapteste, E. (2020) Beyond arbitrium: identification of a second communication system in Bacillus phage phi3T that may regulate host defense mechanisms, ISME J., 15, 545-549, doi: 10.1038/ s41396-020-00795-9.

115. Grayson, P., and Molineux, I. J. (2007) Is phage DNA 'injected' into cells - biologists and physicists can agree, Curr. Opin. Microbiol., 10, 401-409.

116. Labrie, S. J., Samson, J. E., and Moineau, S. (2010) Bacteriophage resistance mechanisms, Nat. Rev. Microbiol., 8, 317-327.

117. Abedon, S. T. (2015) Bacteriophage secondary infection, Virol. Sin., 30, 3-10.

118. Bebeacua, C., Lorenzo Fajardo, J. C., Blangy, S., Spinelli, S., Bollmann, S., et al. (2013) X-ray structure of a superinfection exclusion lipoprotein from phage TP-J34 and identification of the tape measure protein as its target, Mol. Microbiol., 89, 152-65.

119. Ali, Y., Koberg, S., Heßner, S., Sun, X., Rabe, B., et al. (2014) Temperate Streptococcus thermophilus phages expressing superinfection exclusion proteins of the Ltp type, Front. Microbiol., 5, 98.

120. Cumby, N., Edwards, A. M., Davidson, A. R., and Maxwell, K. L. (2012) The bacteriophage HK97 gp15 moron element encodes a novel superinfection exclusion protein, J. Bacteriol., 194, 5012-5019.

121. Cumby, N., Reimer, K., Mengin-Lecreulx, D., Davidson, A. R., and Maxwell, K. L. (2015) The phage tail tape measure protein, an inner membrane protein and a periplasmic chaperone play connected roles in the genome injection process of E. coli phage HK 97, Mol. Microbiol., 96, 437-447.

122. Lu, M. J., and Henning, U. (1994) Superinfection exclusion by T-even-type coliphages, Trends Microbiol., 2, 137-139.

123. Lu, M. J., and Henning, U. (1989) The immunity (imm) gene of Escherichia coli bacteriophage T4, J. Virol., 63, 3472-3478.

124. Ko, C., and Hatfull, G. F. (2018) Mycobacteriophage Fruitloop gp52 inactivates Wag31 (DivIVA) to prevent heterotypic superinfection, Mol. Microbiol., 108, 443-460.

125. Mahony, J., McGrath, S., Fitzgerald, G. F., and van Sinderen, D. (2008) Identification and characterization of lactococcal-prophage-carried superinfection exclusion genes, Appl. Environ. Microbiol., 74, 6206-6215.

126. Hofer, B., Ruge, M., and Dreiseikelmann, B. (1995) The superinfection exclusion gene (sieA) of bacteriophage P22: identification and overexpression of the gene and localization of the gene product, J. Bacteriol., 177, 3080-3086.

127. Nesper, J., Blaß, J., Fountoulakis, M., and Reidl, J. (1999) Characterization of the major control region of Vibrio cholerae bacteriophage K139: immunity, exclusion, and integration, J. Bacteriol., 181, 2902-2913.

128. Kliem, M., and Dreiseikelmann, B. (1989) The superimmunity gene sim of bacteriophage $\mathrm{P} 1$ causes superinfection exclusion, Virology, 171, 350-355.
129. Carballo-Ontiveros, M. A., Cazares, A., Vinuesa, P., Kameyama, L., and Guarneros, G. (2020) The concerted action of two B3-like prophage genes exclude superinfecting bacteriophages by blocking DNA entry into Pseudomonas aeruginosa, J. Virol., 94, e00953-20, doi: 10.1128/JVI.00953-20.

130. Domingo-Calap, P., Mora-Quilis, L., and Sanjuán, R. (2020) Social bacteriophages, Microorganisms, 8, 1-10.

131. Ragunathan, P. T., and Vanderpool, C. K. (2019) Crypticprophage-encoded small protein DicB protects Escherichia coli from phage infection by inhibiting inner membrane receptor proteins, J. Bacteriol., 201, e0047519, doi: 10.1128/JB.00475-19.

132. Dillingham, M. S., and Kowalczykowski, S. C. (2008) RecBCD enzyme and the repair of double-stranded DNA breaks, Microbiol. Mol. Biol. Rev., 72, 642-671.

133. Cheng, K., Wilkinson, M., Chaban, Y., and Wigley, D. B. (2020) A conformational switch in response to Chi converts RecBCD from phage destruction to DNA repair, Nat. Struct. Mol. Biol., 27, 71-77.

134. Raleigh, E. A., and Brooks, J. E. (1998) Restriction modification systems: where they are and what they do, in Bacterial Genomes, Springer, doi: 10.1007/978-1-46156369-3_8.

135. Loenen, W. A. M., Dryden, D. T. F., Raleigh, E. A., Wilson, G. G., and Murray, N. E. (2014) Highlights of the DNA cutters: a short history of the restriction enzymes, Nucleic Acids Res., 42, 3-19.

136. Bertani, G., and Weigle, J. J. (1953) Host controlled variation in bacterial viruses, J. Bacteriol., 65, 113.

137. Luria, S. E. (1953) Host-induced modifications of viruses, in Cold Spring Harbor Symposia on Quantitative Biology, Cold Spring Harbor Laboratory Press, Vol. 18, pp. 237-244.

138. Berg, P., and Mertz, J. E. (2010) Personal reflections on the origins and emergence of recombinant DNA technology, Genetics, 184, 9-17.

139. Roberts, R. J., Belfort, M., Bestor, T., Bhagwat, A. S., Bickle, T. A., et al. (2003) A nomenclature for restriction enzymes, DNA methyltransferases, homing endonucleases and their genes, Nucleic Acids Res., 31, 1805-12.

140. Bower, E. K. M., Cooper, L. P., Roberts, G. A., White, J. H., Luyten, Y., et al. (2018) A model for the evolution of prokaryotic DNA restriction-modification systems based upon the structural malleability of Type I restriction-modification enzymes, Nucleic Acids Res., 46, 9067-9080.

141. Pingoud, A., Fuxreiter, M., Pingoud, V., and Wende, W. (2005) Type II restriction endonucleases: structure and mechanism, Cell. Mol. Life Sci., 62, 685.

142. Pingoud, A., Wilson, G. G., and Wende, W. (2014) Type II restriction endonucleases - a historical perspective and more, Nucleic Acids Res., 42, 7489-7527.

143. Nelson, M., Raschke, E., and McClelland, M. (1993) Effect of site-specific methylation on restriction endonucleases and DNA modification methyltransferases, Nucleic Acids Res., 21, 3139.

144. Morgan, R. D., Bhatia, T. K., Lovasco, L., and Davis, T. B. (2008) MmeI: a minimal Type II restriction-modification system that only modifies one DNA strand for host protection, Nucleic Acids Res., 36, 6558-6570.

145. Janulaitis, A., Petrusyte, M., Maneliene, Z., Klimasauskas, S., and Butkus, V. (1992) Purification and 
properties of the Eco571 restriction endonuclease and methylas - prototypes of a new class (type IV), Nucleic Acids Res., 20, 6043-6049.

146. Sorokin, V., Severinov, K., and Gelfand, M. S. (2009) Systematic prediction of control proteins and their DNA binding sites, Nucleic Acids Res., 37, 441-451.

147. Klimuk, E., Bogdanova, E., Nagornykh, M., Rodic, A., Djordjevic, M., et al. (2018) Controller protein of restriction-modification system Kpn2I affects transcription of its gene by acting as a transcription elongation roadblock, Nucleic Acids Res., 46, 10810-10826.

148. Zakharova, M., Minakhin, L., Solonin, A., and Severinov, K. (2004) Regulation of RNA polymerase promoter selectivity by covalent modification of DNA, J. Mol. Biol., 335, 103-111.

149. Murray, N. E. (2000) Type I restriction systems: sophisticated molecular machines (a legacy of Bertani and Weigle), Microbiol. Mol. Biol. Rev., 64, 412-434.

150. Loenen, W. A. M., Dryden, D. T. F., Raleigh, E. A., and Wilson, G. G. (2014) Type I restriction enzymes and their relatives, Nucleic Acids Res., 42, 20-44.

151. Gao, Y., Cao, D., Zhu, J., Feng, H., Luo, X., et al. (2020) Structural insights into assembly, operation and inhibition of a type I restriction-modification system, Nat. Microbiol., 5, 1107-1118.

152. Neaves, K. J., Cooper, L. P., White, J. H., Carnally, S. M., Dryden, D. T. F., et al. (2009) Atomic force microscopy of the EcoKI Type I DNA restriction enzyme bound to DNA shows enzyme dimerization and DNA looping, Nucleic Acids Res., 37, 2053-2063.

153. Bianco, P. R., and Hurley, E. M. (2005) The type I restriction endonuclease EcoR124I, couples ATP hydrolysis to bidirectional DNA translocation, J. Mol. Biol., 352, 837-859.

154. Janscak, P., MacWilliams, M. P., Sandmeier, U., Nagaraja, V., and Bickle, T. A. (1999) DNA translocation blockage, a general mechanism of cleavage site selection by type I restriction enzymes, EMBO J., 18, 2638-2647.

155. Studier, F. W., and Bandyopadhyay, P. K. (1988) Model for how type I restriction enzymes select cleavage sites in DNA, Proc. Natl. Acad. Sci. USA, 85, 4677-4681.

156. Smith, R. M., Diffin, F. M., Savery, N. J., Josephsen, J., and Szczelkun, M. D. (2009) DNA cleavage and methylation specificity of the single polypeptide restriction-modification enzyme LlaGI, Nucleic Acids Res., 37, 72067218.

157. Chand, M. K., Carle, V., Anuvind, K. G., and Saikrishnan, K. (2020) DNA-mediated coupling of ATPase, translocase and nuclease activities of a Type ISP restriction-modification enzyme, Nucleic Acids Res., 48, 2594-2603.

158. Makovets, S., Titheradge, A. J. B., and Murray, N. E. (1998) ClpX and ClpP are essential for the efficient acquisition of genes specifying type IA and IB restriction systems, Mol. Microbiol., 28, 25-35.

159. Simons, M., Diffin, F. M., and Szczelkun, M. D. (2014) ClpXP protease targets long-lived DNA translocation states of a helicase-like motor to cause restriction alleviation, Nucleic Acids Res., 42, 12082-12091.

160. Dybvig, K., Sitaraman, R., and French, C. T. (1998) A family of phase-variable restriction enzymes with differing specificities generated by high-frequency gene rearrangements, Proc. Natl. Acad. Sci. USA, 95, 13923-13928.
161. Rao, D. N., Dryden, D. T. F., and Bheemanaik, S. (2014) Type III restriction-modification enzymes: a historical perspective, Nucleic Acids Res., 42, 45-55.

162. Butterer, A., Pernstich, C., Smith, R. M., Sobott, F., Szczelkun, M. D., and Toth, J. (2014) Type III restriction endonucleases are heterotrimeric: comprising one helicasenuclease subunit and a dimeric methyltransferase that binds only one specific DNA, Nucleic Acids Res., 42, 5139-5150.

163. Gupta, Y. K., Chan, S.-H., Xu, S., and Aggarwal, A. K. (2015) Structural basis of asymmetric DNA methylation and ATP-triggered long-range diffusion by EcoP15I, Nat. Commun., 6, 1-10.

164. Janscak, P., Sandmeier, U., Szczelkun, M. D., and Bickle, T. A. (2001) Subunit assembly and mode of DNA cleavage of the type III restriction endonucleases EcoP1I and EcoP15I, J. Mol. Biol., 306, 417-431.

165. Van Aelst, K., Tyth, J., Ramanathan, S. P., Schwarz, F. W., Seidel, R., and Szczelkun, M. D. (2010) Type III restriction enzymes cleave DNA by long-range interaction between sites in both head-to-head and tail-to-tail inverted repeat, Proc. Natl. Acad. Sci., 107, 9123-9128.

166. Schwarz, F. W., Tóth, J., van Aelst, K., Cui, G., Clausing, S., et al. (2013) The helicase-like domains of type III restriction enzymes trigger long-range diffusion along DNA, Science, 340, 353-356.

167. Ahmad, I., Kulkarni, M., Gopinath, A., and Saikrishnan, K. (2018) Single-site DNA cleavage by Type III restriction endonuclease requires a site-bound enzyme and a trans-acting enzyme that are ATPase-activated, Nucleic Acids Res., 46, 6229-6237.

168. Srikhanta, Y. N., Fox, K. L., and Jennings, M. P. (2010) The phasevarion: phase variation of type III DNA methyltransferases controls coordinated switching in multiple genes, Nat. Rev. Microbiol., 8, 196-206.

169. Weigele, P., and Raleigh, E. A. (2016) Biosynthesis and function of modified bases in bacteria and their viruses, Chem. Rev., 116, 12655-12687.

170. Tock, M. R., and Dryden, D. T. (2005) The biology of restriction and anti-restriction, Curr. Opin. Microbiol., 8, 466-472.

171. Loenen, W. A. M., and Raleigh, E. A. (2014) The other face of restriction: modification-dependent enzymes, Nucleic Acids Res., 42, 56-69.

172. Czapinska, H., Kowalska, M., Zagorskaitè, E., Manakova, E., Slyvka, A., et al. (2018) Activity and structure of EcoKMcrA, Nucleic Acids Res., 46, 9829-9841.

173. Siwek, W., Czapinska, H., Bochtler, M., Bujnicki, J. M., and Skowronek, K. (2012) Crystal structure and mechanism of action of the N6-methyladenine-dependent type IIM restriction endonuclease R.DpnI, Nucleic Acids Res., 40, 7563-7572.

174. Liu, G., Ou, H.-Y., Wang, T., Li, L., Tan, H., et al. (2010) Cleavage of phosphorothioated DNA and methylated DNA by the type IV restriction endonuclease ScoMcrA, PLoS Genet., 6, e1001253.

175. Sutherland, E., Coe, L., and Raleigh, E. A. (1992) McrBC: a multisubunit GTP-dependent restriction endonuclease, J. Mol. Biol., 225, 327-348.

176. Xu, S., Corvaglia, A. R., Chan, S.-H., Zheng, Y., and Linder, P. (2011) A type IV modification-dependent restriction enzyme SauUSI from Staphylococcus aureus subsp. aureus USA300, Nucleic Acids Res., 39, 5597-5610. 
177. Vasu, K., and Nagaraja, V. (2013) Diverse functions of restriction-modification systems in addition to cellular defense, Microbiol. Mol. Biol. Rev., 77, 53-72.

178. Murphy, J., Mahony, J., Ainsworth, S., Nauta, A., and van Sinderen, D. (2013) Bacteriophage orphan DNA methyltransferases: insights from their bacterial origin, function, and occurrence, Appl. Environ. Microbiol., 79, 7547-7555.

179. Adhikari, S., and Curtis, P. D. (2016) DNA methyltransferases and epigenetic regulation in bacteria, FEMS Microbiol. Rev., 40, 575-591.

180. Kobayashi, I. (2001) Behavior of restriction-modification systems as selfish mobile elements and their impact on genome evolution, Nucleic Acids Res., 29, 3742-3756.

181. Ershova, A. S., Rusinov, I. S., Spirin, S. A., Karyagina, A. S., and Alexeevski, A. V. (2015) Role of restriction-modification systems in prokaryotic evolution and ecology, Biochemistry (Moscow), 80, 1373-1386.

182. Seib, K. L., Srikhanta, Y. N., Atack, J. M., and Jennings, M. P. (2020) Epigenetic regulation of virulence and immunoevasion by phase-variable restriction-modification systems in bacterial pathogens, Annu. Rev. Microbiol., 74, 655-671.

183. Dimitriu, T., Szczelkun, M. D., and Westra, E. R. (2020) Evolutionary ecology and interplay of prokaryotic innate and adaptive immune systems, Curr. Biol., 30, R1189-R1202.

184. Lomovskaia, N. D., Mkrtumian, N. M., and Gostimskaya, N. L. (1970) Isolation and characterization of the actinophage of Streptomyces coelicolor, Genetica, 6, 135.

185. Chinenova, T. A., Mkrtumian, N. M., and Lomovskaia, N. D. (1982) Genetic characteristics of a new phage resistance trait in Streptomyces coelicolor A3(2), Genetika, 18, 1945-1952.

186. Chater, K. F. (1986) Streptomyces phages and their applications to Streptomyces genetics, in The Bacteria, Academic Press Orlando, vol. 9, pp. 119-158.

187. Bedford, D. J., Laity, C., and Buttner, M. J. (1995) Two genes involved in the phase-variable phi C31 resistance mechanism of Streptomyces coelicolor A3(2), J. Bacteriol., 177, 4681-4689.

188. Laity, C., Chater, K. F., Lewis, C. G., and Buttner, M. J. (1993) Genetic analysis of the phi C31-specific phage growth limitation $(\mathrm{Pgl})$ system of Streptomyces coelicolor A3(2), Mol. Microbiol., 7, 329-336.

189. Sumby, P., and Smith, M. C. M. (2002) Genetics of the phage growth limitation (Pgl) system of Streptomyces coelicolor A3(2), Mol. Microbiol., 44, 489-500.

190. Hoskisson, P. A., Sumby, P., and Smith, M. C. M. (2015) The phage growth limitation system in Streptomyces coelicolor $\mathrm{A}(3) 2$ is a toxin/antitoxin system, comprising enzymes with DNA methyltransferase, protein kinase and ATPase activity, Virology, 477, 100-109.

191. Goldfarb, T., Sberro, H., Weinstock, E., Cohen, O., Doron, S., et al. (2015) BREX is a novel phage resistance system widespread in microbial genomes, EMBO J., 34, 169-183.

192. Pu, T., Mei, Z., Zhang, W., Liang, W., Zhou, X., et al. (2020) An in vitro DNA phosphorothioate modification reaction, Mol. Microbiol., 113, 452-463.

193. Gordeeva, J., Morozova, N., Sierro, N., Isaev, A., Sinkunas, T., et al. (2019) BREX system of Escherichia coli distinguishes self from non-self by methylation of a specific DNA site, Nucleic Acids Res., 47, 253-265.

194. LeGault, K., Hays, S. G., Angermeyer, A., McKitterick, A. C., Johura, F., et al. (2020) Temporal shifts in antibiot- ic resistance elements govern virus-pathogen conflicts, bioRxiv, doi: 10.1101/2020.12.16.423150.

195. Hui, W., Zhang, W., Kwok, L.-Y., Zhang, H., Kong, J., and Sun, T. (2019) Identification and functional analysis of the pglX gene of Lactobacillus casei Zhang bacteriophage exclusive (BREX) system, Appl. Environ. Microbiol., AEM-01001.

196. Atanasiu, C., Su, T. J., Sturrock, S. S., and Dryden, D. T. F. (2002) Interaction of the ocr gene 0.3 protein of bacteriophage T7 with Eco KI restriction/modification enzyme, Nucleic Acids Res., 30, 3936-3944.

197. Bandyopadhyay, P. K., Studier, F. W., Hamilton, D. L., and Yuan, R. (1985) Inhibition of the type I restrictionmodification enzymes EcoB and EcoK by the gene 0.3 protein of bacteriophage T7, J. Mol. Biol., 182, 567-578.

198. Ofir, G., Melamed, S., Sberro, H., Mukamel, Z., Silverman, S., et al. (2018) DISARM is a widespread bacterial defense system with broad anti-phage activities, Nat. Microbiol., 3, 90-98.

199. Mahankali, M., Alter, G., and Gomez-Cambronero, J. (2015) Mechanism of enzymatic reaction and proteinprotein interactions of PLD from a 3D structural model, Cell. Signal., 27, 69-81.

200. Thiaville, J. J., Kellner, S. M., Yuan, Y., Hutinet, G., Thiaville, P. C., et al. (2016) Novel genomic island modifies DNA with 7-deazaguanine derivatives, Proc. Natl. Acad. Sci. USA, 113, E1452-E1459.

201. Iyer, L. M., Zhang, D., Maxwell Burroughs, A., and Aravind, L. (2013) Computational identification of novel biochemical systems involved in oxidation, glycosylation and other complex modifications of bases in DNA, Nucleic Acids Res., 41, 7635-7655.

202. Hutinet, G., Kot, W., Cui, L., Hillebrand, R., Balamkundu, S., et al. (2019) 7-Deazaguanine modifications protect phage DNA from host restriction systems, Nat. Commun., 10, 1-12.

203. Kot, W., Olsen, N. S., Nielsen, T. K., Hutinet, G., de Crécy-Lagard, V., et al. (2020) Detection of preQ0 deazaguanine modifications in bacteriophage CAjan DNA using Nanopore sequencing reveals same hypermodification at two distinct DNA motifs, Nucleic Acids Res., 48, 1038310396.

204. Wang, L., Jiang, S., Deng, Z., Dedon, P. C., and Chen, S. (2019) DNA phosphorothioate modification - a new multi-functional epigenetic system in bacteria, FEMS Microbiol. Rev., 43, 109-122.

205. Xiong, L., Liu, S., Chen, S., Xiao, Y., Zhu, B., et al. (2019) A new type of DNA phosphorothioation-based antiviral system in archaea, Nat. Commun., 10, 1-11.

206. Xiong, X., Wu, G., Wei, Y., Liu, L., Zhang, Y., et al. (2020) SspABCD-SspE is a phosphorothioation-sensing bacterial defense system with broad anti-phage activities, Nat. Microbiol., 5, 917-928.

207. Zhou, X., He, X., Liang, J., Li, A., Xu, T., et al. (2005) A novel DNA modification by sulphur, Mol. Microbiol., 57, 1428-1438.

208. Wang, L., Chen, S., Xu, T., Taghizadeh, K., Wishnok, J. S., et al. (2007) Phosphorothioation of DNA in bacteria by dnd genes, Nat. Chem. Biol., 3, 709-710.

209. He, W., Huang, T., Tang, Y., Liu, Y., Wu, X., et al. (2015) Regulation of DNA phosphorothioate modification in Salmonella enterica by DndB, Sci. Rep., 5, 12368. 
210. You, D., Wang, L., Yao, F., Zhou, X., and Deng, Z. (2007) A Novel DNA Modification by sulfur: DndA is a NifS-like cysteine desulfurase capable of assembling DndC as an iron-sulfur cluster protein in Streptomyces lividans, Biochemistry, 46, 6126-6133.

211. Yao, F., Xu, T., Zhou, X., Deng, Z., and You, D. (2009) Functional analysis of spfD gene involved in DNA phosphorothioation in Pseudomonas fluorescens Pf0-1, FEBS Lett., 583, 729-733.

212. Wu, Y., Tang, Y., Dong, X., Zheng, Y. Y., Haruehanroengra, P., et al. (2020) RNA phosphorothioate modification in prokaryotes and eukaryotes, ACS Chem. Biol., 15, 1301-1305.

213. Tong, T., Chen, S., Wang, L., Tang, Y., Ryu, J. Y., et al. (2018) Occurrence, evolution, and functions of DNA phosphorothioate epigenetics in bacteria, Proc. Natl. Acad. Sci., 115, E2988-E2996.

214. Xu, T., Yao, F., Zhou, X., Deng, Z., and You, D. (2010) A novel host-specific restriction system associated with DNA backbone S-modification in Salmonella, Nucleic Acids Res., 38, 7133-41.
215. Cao, B., Cheng, Q., Gu, C., Yao, F., DeMott, M. S., et al. (2014) Pathological phenotypes and in vivo DNA cleavage by unrestrained activity of a phosphorothioate-based restriction system in Salmonella, Mol. Microbiol., 93, 776-785.

216. Gan, R., Wu, X., He, W., Liu, Z., Wu, S., et al. (2014) DNA phosphorothioate modifications influence the global transcriptional response and protect DNA from doublestranded breaks, Sci. Rep., 4, 6642.

217. Cao, B., Chen, C., DeMott, M. S., Cheng, Q., Clark, T. A., et al. (2014) Genomic mapping of phosphorothioates reveals partial modification of short consensus sequences, Nat. Commun., 5, 1-13.

218. Li, J., Chen, Y., Zheng, T., Kong, L., Zhu, S., et al. (2019) Quantitative mapping of DNA phosphorothioatome reveals phosphorothioate heterogeneity of low modification frequency, PLoS Genet., 15, e1008026.

219. Wu, X., Cao, B., Aquino, P., Chiu, T.-P., Chen, C., et al. (2020) Epigenetic competition reveals density-dependent regulation and target site plasticity of phosphorothioate epigenetics in bacteria, Proc. Natl. Acad. Sci. USA, 117, 14322-14330, doi: 10.1073/pnas.2002933117. 